\title{
A State-of-the-Art Scoping Review on SARS-CoV-2 in Sewage Focusing on the Potential of Wastewater Surveillance for the Monitoring of the COVID-19 Pandemic
}

\author{
G. Bonanno Ferraro ${ }^{1}$ - C. Veneri $\cdot$ P. Mancini ${ }^{1} \cdot$ M. Iaconelli ${ }^{1} \cdot$ E. Suffredini ${ }^{2} \cdot$ L. Bonadonna ${ }^{1} \cdot$ L. Lucentini $^{1}$. \\ A. Bowo-Ngandji ${ }^{3}$. C. Kengne-Nde ${ }^{4}$. D. S. Mbaga ${ }^{3} \cdot$ G. Mahamat $^{3}$. H. R. Tazokong ${ }^{3}$. J. T. Ebogo-Belobo ${ }^{5}$. \\ R. Njouom ${ }^{6} \cdot$ S. Kenmoe ${ }^{6} \cdot$ G. La Rosa ${ }^{1}$ (1)
}

Received: 10 July 2021 / Accepted: 21 September 2021 / Published online: 2 November 2021

(c) The Author(s), under exclusive licence to Springer Science+Business Media, LLC, part of Springer Nature 2021

\begin{abstract}
The outbreak of coronavirus infectious disease-2019 (COVID-19), caused by the Severe Acute Respiratory Syndrome Coronavirus 2 (SARS-CoV-2), has rapidly spread throughout the world. Several studies have shown that detecting SARS-CoV-2 in untreated wastewater can be a useful tool to identify new outbreaks, establish outbreak trends, and assess the prevalence of infections. On 06 May 2021, over a year into the pandemic, we conducted a scoping review aiming to summarize research data on SARS-CoV-2 in sewage. Papers dealing with raw sewage collected at wastewater treatment plants, sewer networks, septic tanks, and sludge treatment facilities were included in this review. We also reviewed studies on sewage collected in community settings such as private or municipal hospitals, healthcare facilities, nursing homes, dormitories, campuses, airports, aircraft, and cruise ships. The literature search was conducted using the electronic databases PubMed, EMBASE, and Web Science Core Collection. This comprehensive research yielded 1090 results, 66 of which met the inclusion criteria and are discussed in this review. Studies from 26 countries worldwide have investigated the occurrence of SARS-CoV-2 in sewage of different origin. The percentage of positive samples in sewage ranged from 11.6 to $100 \%$, with viral concentrations ranging from ${ }^{<} \mathrm{LOD}$ to $4.6 \times 10^{8}$ genome copies/L. This review outlines the evidence currently available on wastewater surveillance: (i) as an early warning system capable of predicting COVID-19 outbreaks days or weeks before clinical cases; (ii) as a tool capable of establishing trends in current outbreaks; (iii) estimating the prevalence of infections; and (iv) studying SARS-CoV-2 genetic diversity. In conclusion, as a cost-effective, rapid, and reliable source of information on the spread of SARS-CoV-2 and its variants in the population, wastewater surveillance can enhance genomic and epidemiological surveillance with independent and complementary data to inform public health decision-making during the ongoing pandemic.
\end{abstract}

G. La Rosa

giuseppina.larosa@iss.it

1 Department of Environment and Health, Istituto Superiore di Sanità, Rome, Italy

2 Department of Food Safety, Nutrition and Veterinary Public Health, Istituto Superiore di Sanità, Rome, Italy

3 Department of Microbiology, The University of Yaounde I, Yaounde, Cameroon

4 Research Monitoring and Planning Unit, National Aids Control Committee, Douala, Cameroon

5 Medical Research Centre, Institute of Medical Research and Medicinal Plants Studies, Yaounde, Cameroon

6 Virology Department, Centre Pasteur of Cameroon, Yaounde, Cameroon 


\section{Graphic Abstract}

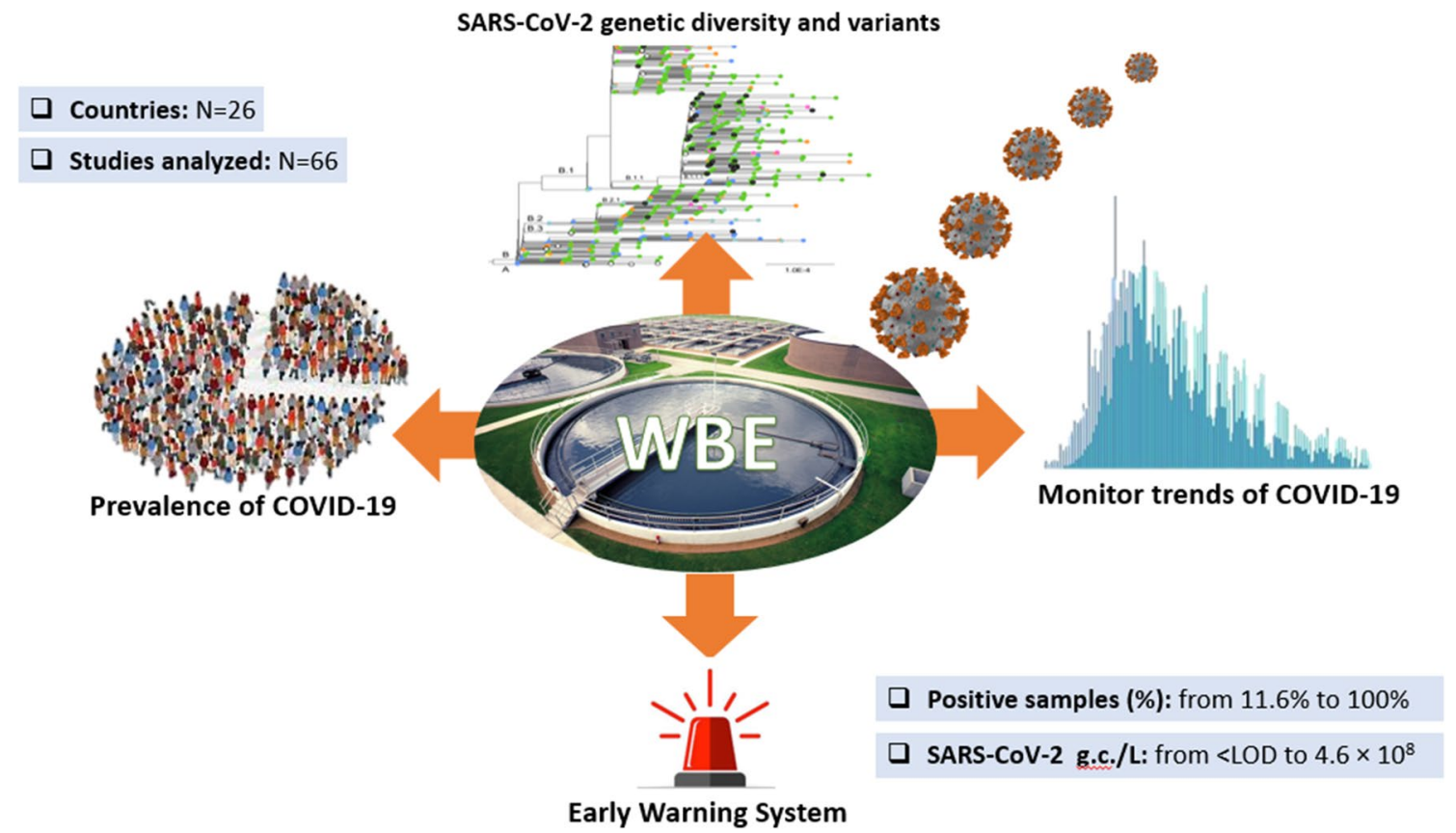

Keywords COVID-19 $\cdot$ SARS-CoV-2 $\cdot$ Wastewater $\cdot$ Surveillance $\cdot$ Sewage

\section{Introduction}

Coronavirus disease-2019 (COVID-19) emerged in China in December 2019 and has since become a global pandemic, with over 180.000 .000 confirmed cases globally and 3.900.000 deaths as of July 03, 2021 (WHO, 2021). The true number of cases is likely to have been substantially greater than reported, since mild or asymptomatic infections have often been overlooked. On March 11, 2020, "deeply concerned by the alarming levels of spread and severity, and by the alarming levels of inaction", WHO declared COVID-19 a global pandemic (WHO, 2020). Currently, the epidemiological scenario varies among countries, depending on their epidemic phase and mitigation measures. A growing number of SARS-CoV-2 variant sequences have been detected since the beginning of the pandemic, some of which are considered of global concern for possible increased transmissibility, virulence, or ability to evade host immune response (WHO, 2021).

The clinical manifestations of COVID-19 range from asymptomatic or mild to life-threatening disease. Symptoms are mainly respiratory. COVID-19 pneumonia can lead to severe respiratory distress requiring mechanical ventilation, multiple organ failure, and death (Ruan et al., 2020; Wu \& McGoogan, 2020). Nevertheless, gastrointestinal infections have been reported, with symptoms such as diarrhea, nausea, vomiting, and abdominal pain (Alberca et al. 2021a).

Significant concentrations of SARS-CoV-2 RNA have been detected in the feces of infected individuals, both asymptomatic and symptomatic, even after recovery from respiratory symptoms (Alberca et al., 2021, Dergram et al., 2021; Joukar et al., 2021; Nishiura et al., 2020, Pedersen et al., 2021; Petrillo et al., 2021; Treibel et al., 2020, Wölfel et al., 2020; Wu et al., 2021; Zhang et al., 2021), with concentrations up to $10^{7}$ copies per gram of feces, depending on the course of infection (Guo et al., 2021; Saawarn \& Hait, 2021). This has raised concerns about the possibility of fecal-oral transmission of the virus, although the main infection routes are currently believed to be by respiratory droplets, airborne transmission, and direct or indirect contact (Greenhalgh et al., 2021; Lodder \& de Roda Husman, 2020; van Doorn et al., 2020).

Given that SARS-CoV-2 RNA is detectable in feces, testing for it in sewersheds enables the monitoring of disease burden in the community. Thus far, SARS-CoV-2 RNA has been found in raw sewage and primary sludge worldwide, as well as in treated wastewater and river water (Amahmid et al., 2021; Foladori et al., 2020; Mohapatra et al., 2021). Contrary to clinical reporting systems, wastewater surveillance has the advantage of covering not only symptomatic individuals who had been tested, but also asymptomatic and 
symptomatic cases who had not been tested. It is, thus, an excellent tool to complement the clinical surveillance of populations under the threat of COVID-19.

This scoping review provides an overview of the studies published on SARS-CoV-2 wastewater analysis over a year into the pandemic. Its aim is to outline the current evidence regarding the potential of wastewater surveillance: (i) as an early warning system to identify early signs of outbreaks; (ii) to monitor trends in ongoing outbreaks (presence/absence, stagnation/increase/decrease in the number of cases); (iii) to estimate the prevalence of infections; and (iv) to study SARS-CoV-2 genetic diversity and variants in the community.

\section{Methods}

An electronic literature search was conducted on 06 May 2021, using the electronic databases PubMed, EMBASE, and Web Science Core Collection, with no restrictions on publication date or language. The search strategy included terms related to SARS-CoV-2 and the environmental matrix of interest (Supplementary Table S1).

A total of 1090 articles were retrieved. After the removal of duplicates $(n=537)$, the remaining 553 articles were manually screened using the Rayyan review platform (Ouzzani et al., 2016), and assessed for eligibility by two independent reviewers (GLR and GBF). All articles dealing with (i) early warning to identify signs of outbreaks; (ii) trends in ongoing outbreaks (presence/absence, stagnation/increase/decrease in the number of cases); (iii) estimating the prevalence of infections; (iv) studying SARS-CoV-2 genetic diversity and variants in the community, were included in the study. Preprint articles were not included in this review. Based on these inclusion criteria, 432 records were excluded, leaving 121 articles. These were subjected to full-text screening, resulting in the exclusion of an additional 55 papers, which were either (i) unrelated to the detection of SARS-CoV-2 in sewage or to wastewater surveillance (e.g., articles dealing with the standardization of methods or disinfection procedures) (ii) reviews including data already retrieved directly from research articles.

Ultimately, 66 articles were included in the review. A flow chart illustrating the steps of paper selection can be found in Fig. 1.

\section{Results}

The presence of SARS CoV-2 in sewage of different origin has been reported in a total of 26 countries, spanning practically all the continent (Europe, Americas, Asia, Oceania, and Africa). Sixty-six studies, conducted since the beginning of the pandemic, are reviewed and classified here, according to the type of sewage, into three different categories: raw sewage $(n=63)$, sludge $(n=7)$ and septic tank $(n=1)$. Five studies covered more than one sewage type (Chakraborty et al., 2021, D'Aoust et al. 2021b, Graham et al., 2021, Li et al., 2021a, Petala et al., 2021).

Details of the 66 studies (country, category, origin of sewage) are shown in Table 1 and in supplementary Table 2. For each study, information regarding country, sample type, collection time, number of Wastewater Treatment Plants (WWTPs) involved, percentages of positive samples and relative concentrations were retrieved (Table 1). The vast majority of the studies focused on samples collected in WWTPs $(\mathrm{n}=57)$, followed by hospitals $(n=8)$, aircraft $(n=2)$, dormitories $(n=2)$, a sewer network $(n=1)$, a nursing home $(n=1)$, a COVID-19 isolation center $(n=1)$, a cruise ship $(n=1)$, a campus $(n=1)$ and a private residence $(n=1)$. The number of sewage treatment plants included in each study ranged from 2 to 33 . The percentage of SARSCoV-2 positive samples ranged from 11.6 to $100 \%$, and the concentrations of SARS-CoV-2 in wastewater ranged from ${ }^{<} \mathrm{LOD}$ to $4.6 \times 10^{8}$ genome copies (g.c.)/L (see Table 1).

The main findings (summarized in Table S2) are presented here according to the following main areas:

i Wastewater surveillance as an early warning system;

ii Wastewater surveillance to assess infection occurrence and trends, and its correlation with epidemiological measures;

iii Wastewater surveillance to estimate the prevalence of COVID-19 and its power to detect SARS-CoV-2 in a sewershed;

iv Wastewater surveillance to investigate SARS-CoV-2 genetic diversity and variants.

Some of the studies are relevant to more than one of these categories.

\section{Wastewater Surveillance as an Early Warning System}

Twenty-five studies reported either the detection of SARSCoV-2 in the environment before the identification of clinical cases, or a rise in SARS-CoV-2 concentrations in the environment before these trends became visible in the numbers of cases or hospitalizations (Agrawal et al., 2021a; Ahmed et al., 2021 a; Betancourt et al., 2021; Chavarria-Miró et al., 2021; Colosi et al., 2021; D'Aoust et al., 2021b; Davó et al., 2021; Fongaro et al., 2021; Gibas et al., 2021; Gonçalves et al., 2021; Hata et al., 2021; Karthikeyan et al., 2021; Kumar et al., 2021; La Rosa et al., 2020, 2021a; Medema et al., 2020; Peccia et al., 2020; Prado et al., 2020, 2021; Randazzo et al., 2020a, 2020b; Saguti et al., 2021; Trottier et al., 2020; Wilder et al., 2021; Wurtzer et al., 2020). 


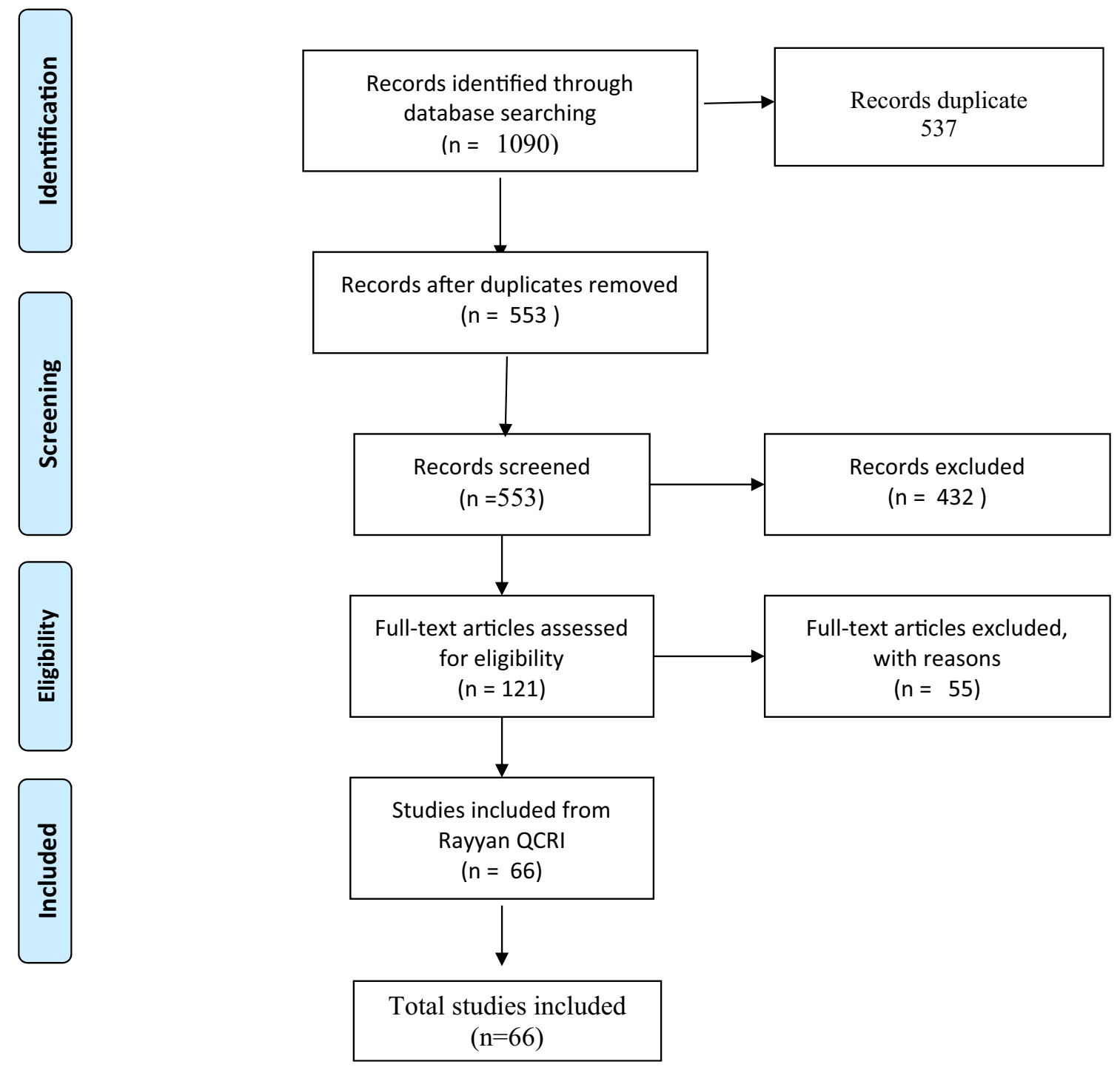

Fig. 1 PRISMA flow diagram

i. Occurrence of SARS-CoV-2 RNA in wastewater where no COVID-19 cases had been reported before.

Two studies - one from Italy and one from Brazil - reported on the occurrence of SARS-CoV-2 as early as December 2019. Both studies used archival samples. The former found SARS-CoV-2 in sewage two months before the first autochthonous case was reported in Italy (La Rosa et al., 2021a), and the latter, more than 90 days ahead of the reports of COVID19 cases in Brazil (Fongaro et al., 2021). Five other studies reported the occurrence of SARS-CoV-2 in wastewater prior to confirmed cases, 6 to 41 days ahead: in Amersfoort, the Netherlands (Medema et al., 2020), in Brazil, in the state of Rio de Janeiro (Prado et al., 2020, 2021), in Connecticut, USA (Peccia et al., 2020), in Spain, in low prevalence municipali- ties (Randazzo et al., 2020b), and in the metropolitan area of Barcelona (Chavarria-Miró et al., 2021), and in Brisbane, Australia (Ahmed et al., 2021a).

ii. Occurrence of SARS-CoV-2 RNA in wastewater at the very beginning of the epidemic, when. COVID-19 cases were only incipient, or in low prevalence periods

Five studies detected SARS-CoV-2 RNA in wastewater or primary clarified sludge when the number of officially confirmed cases was still very low: in Milan, Italy, in February 2020 at a time when only 29 cases had been officially reported in the province (La Rosa et al., 2020), in France, in March and April 2020, when only 635 cases were reported in the whole country (Wurtzer et al., 2020), in the region of Valencia, Spain, in late February 2020, when COVID-19 cases were only incipient (Randazzo et al., 2020a), in 


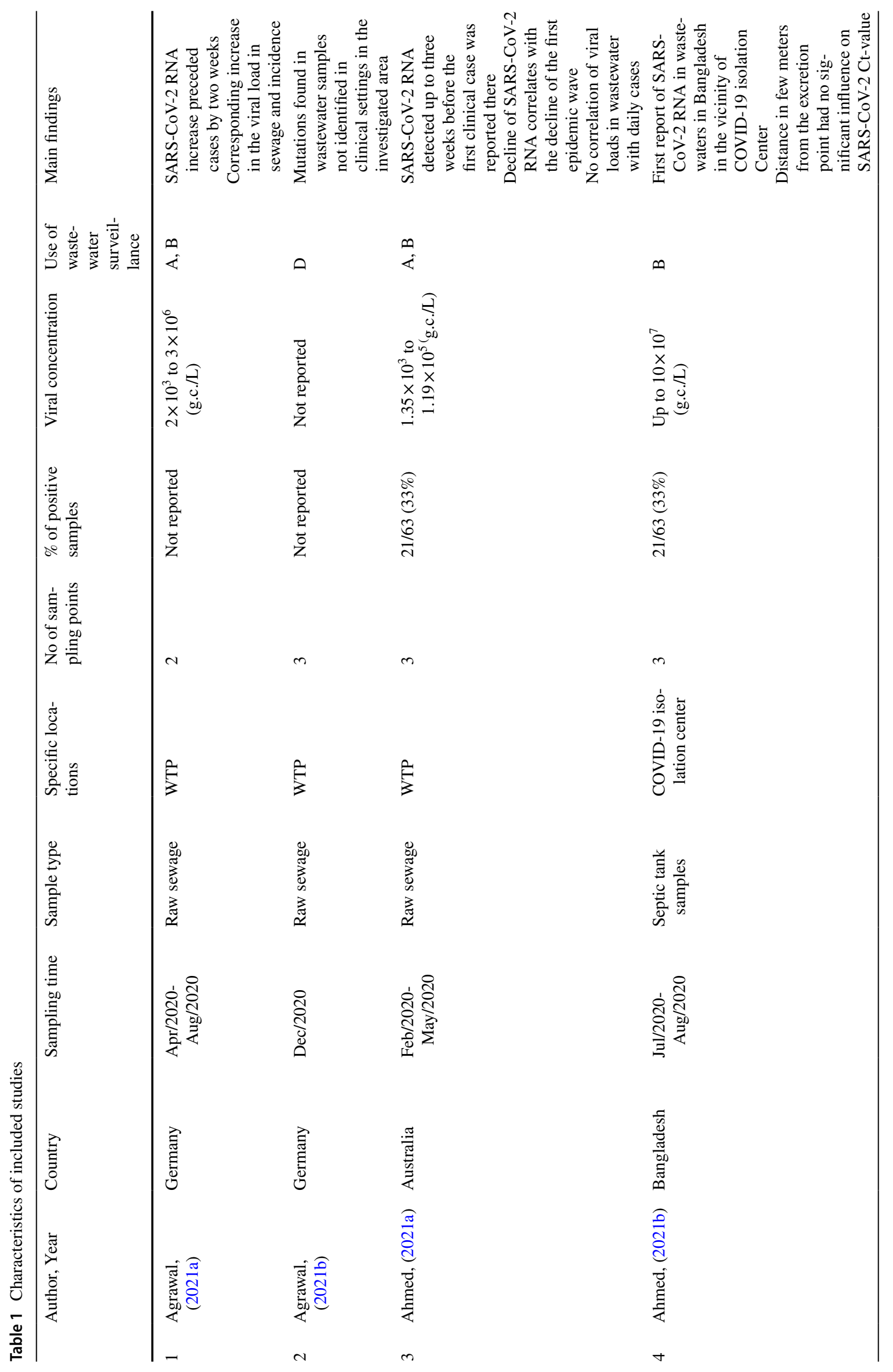




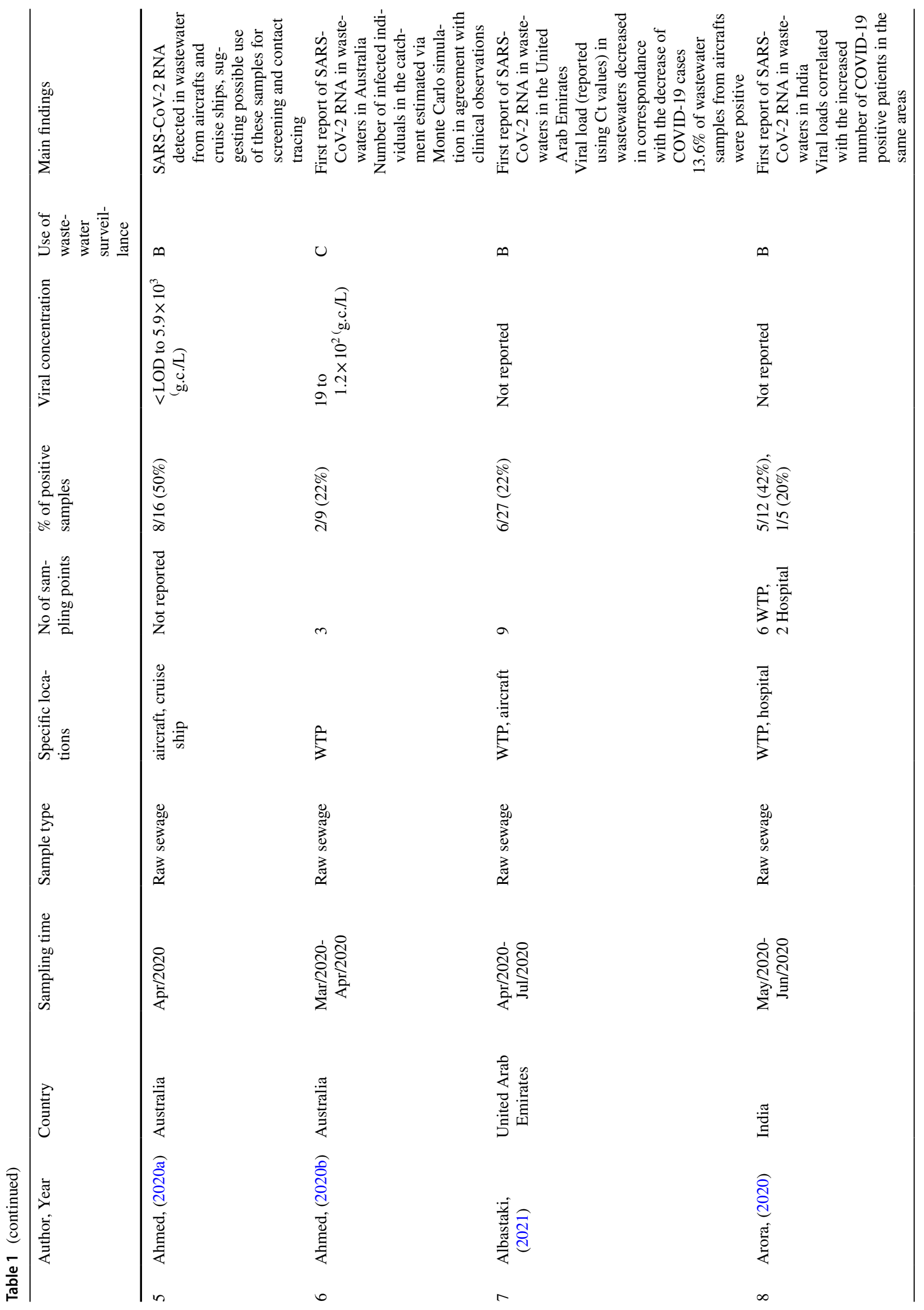




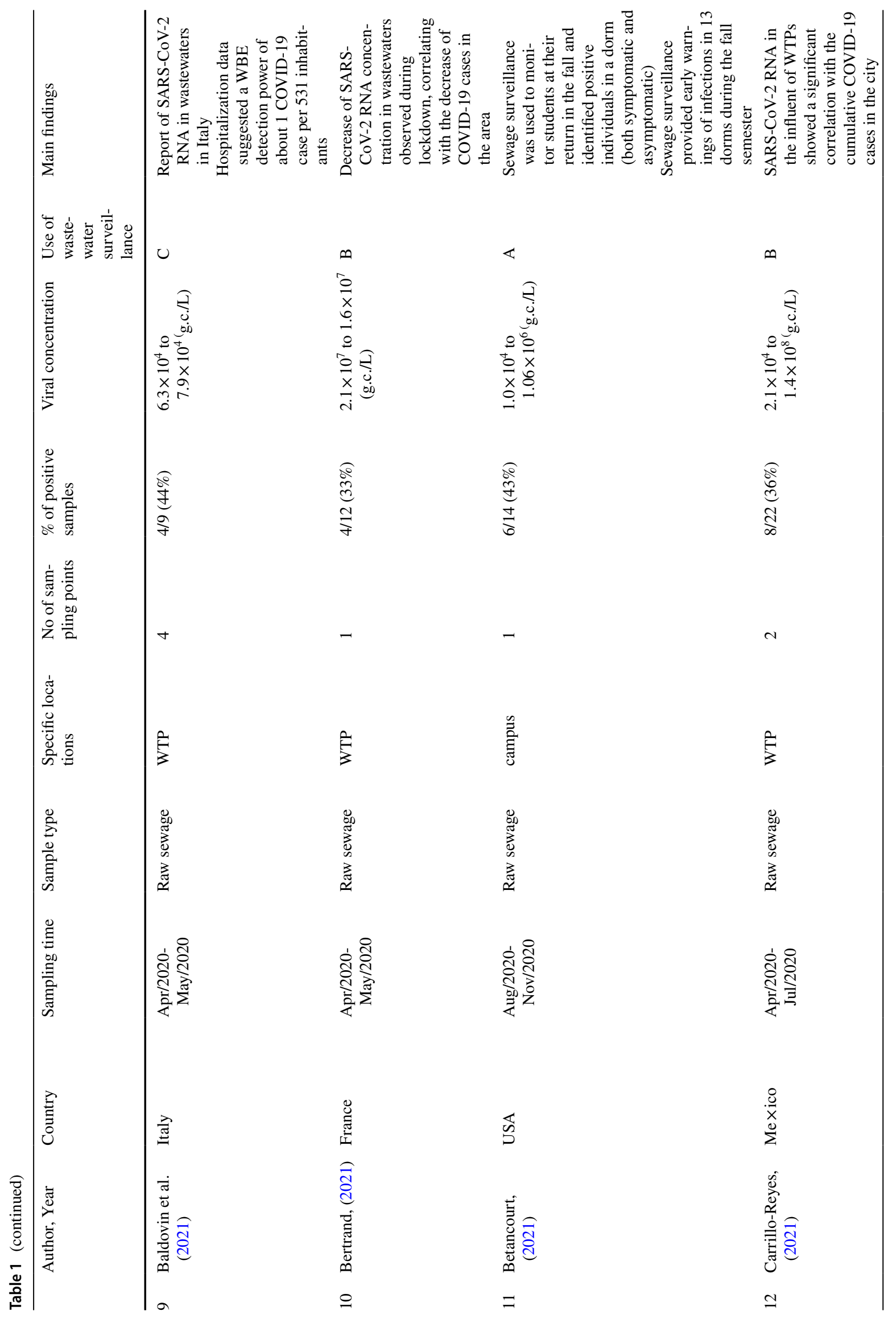




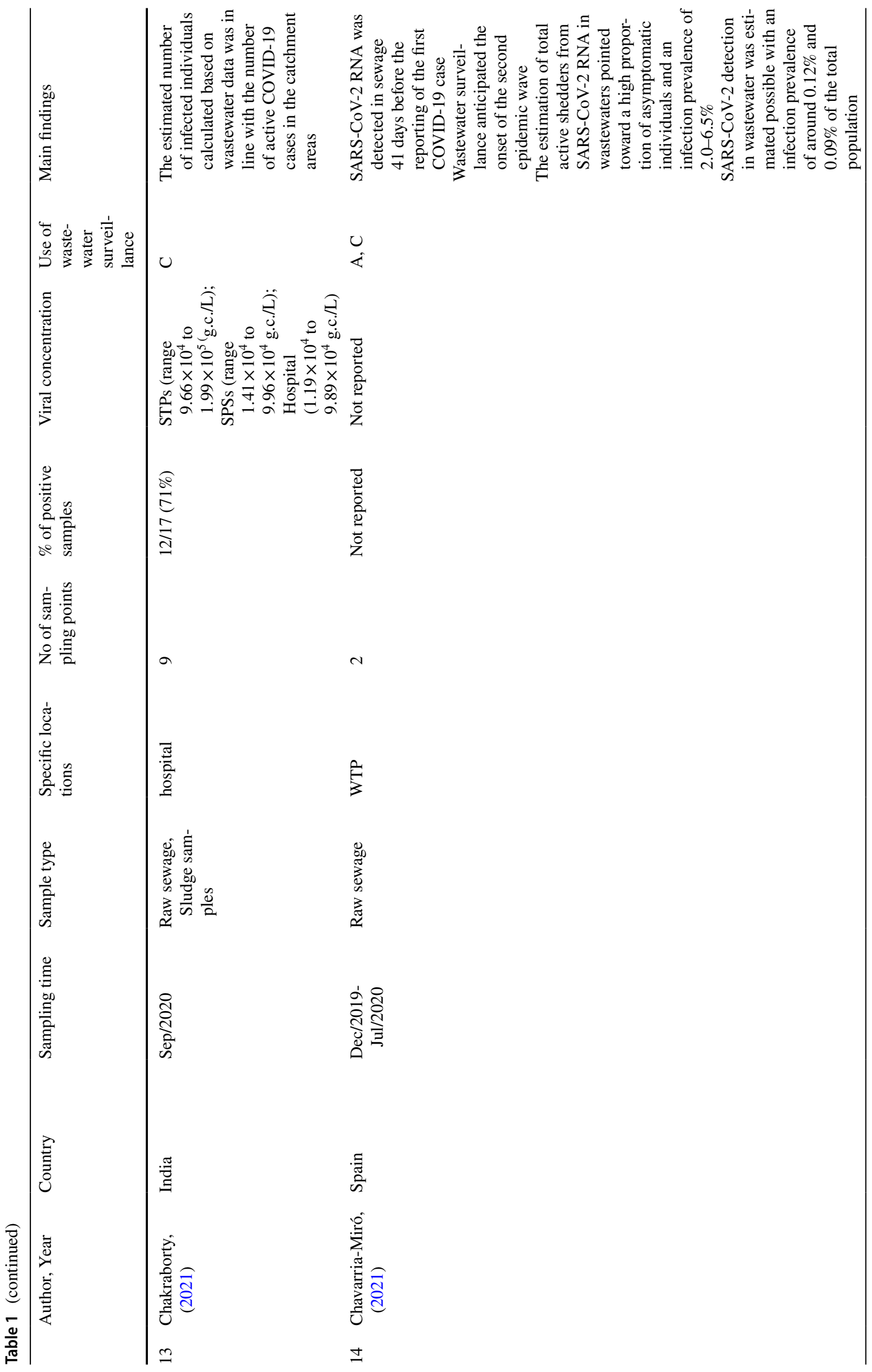




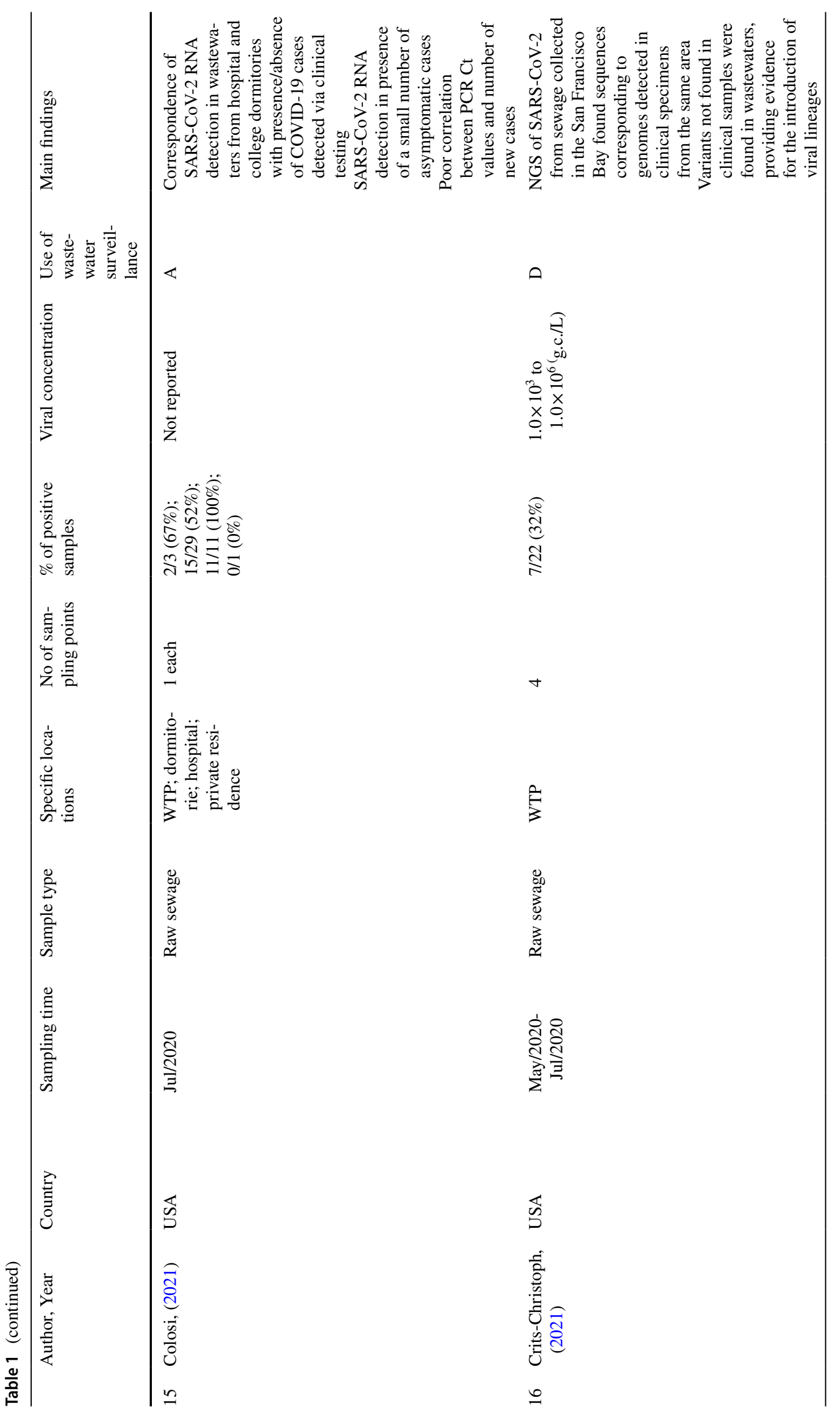




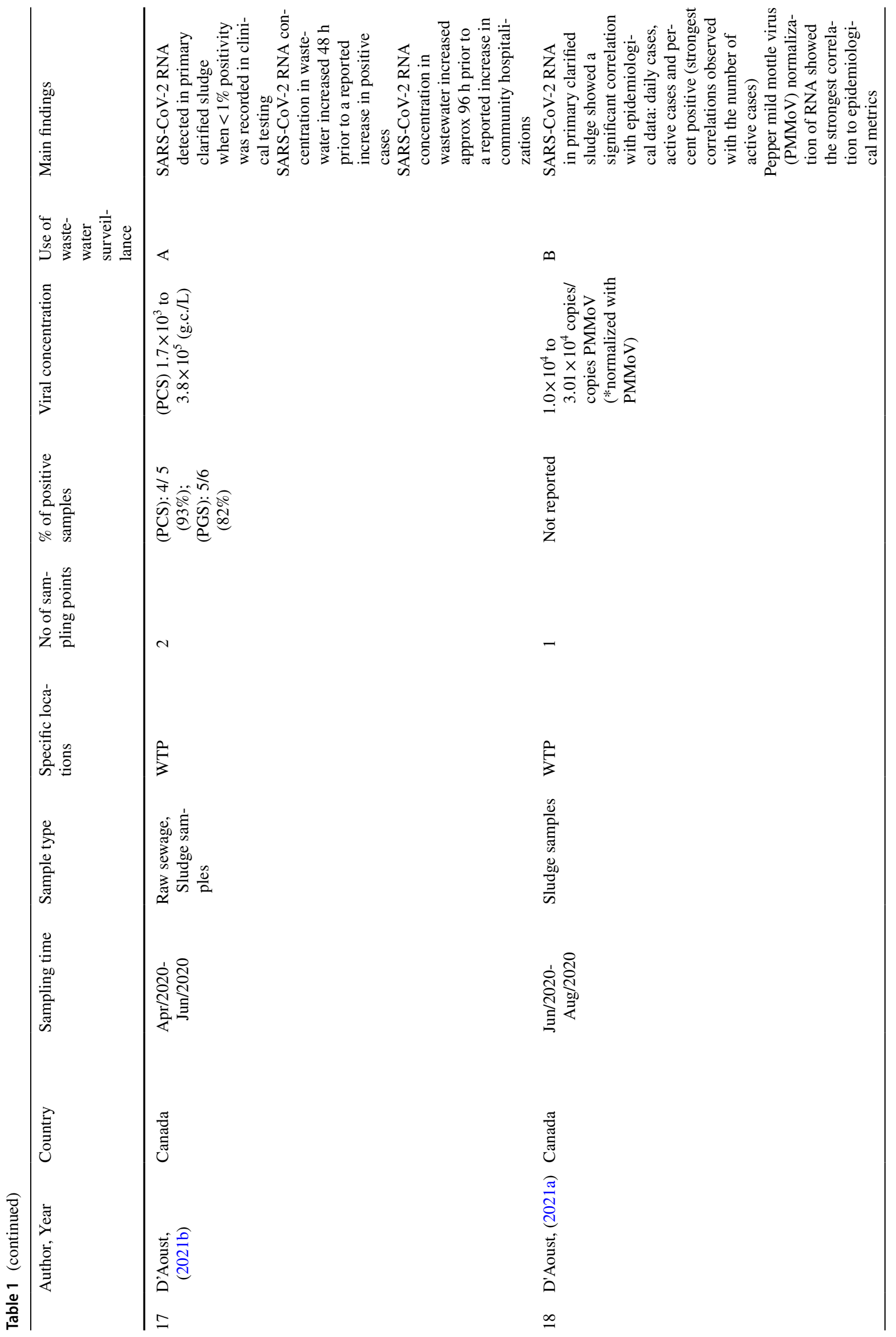




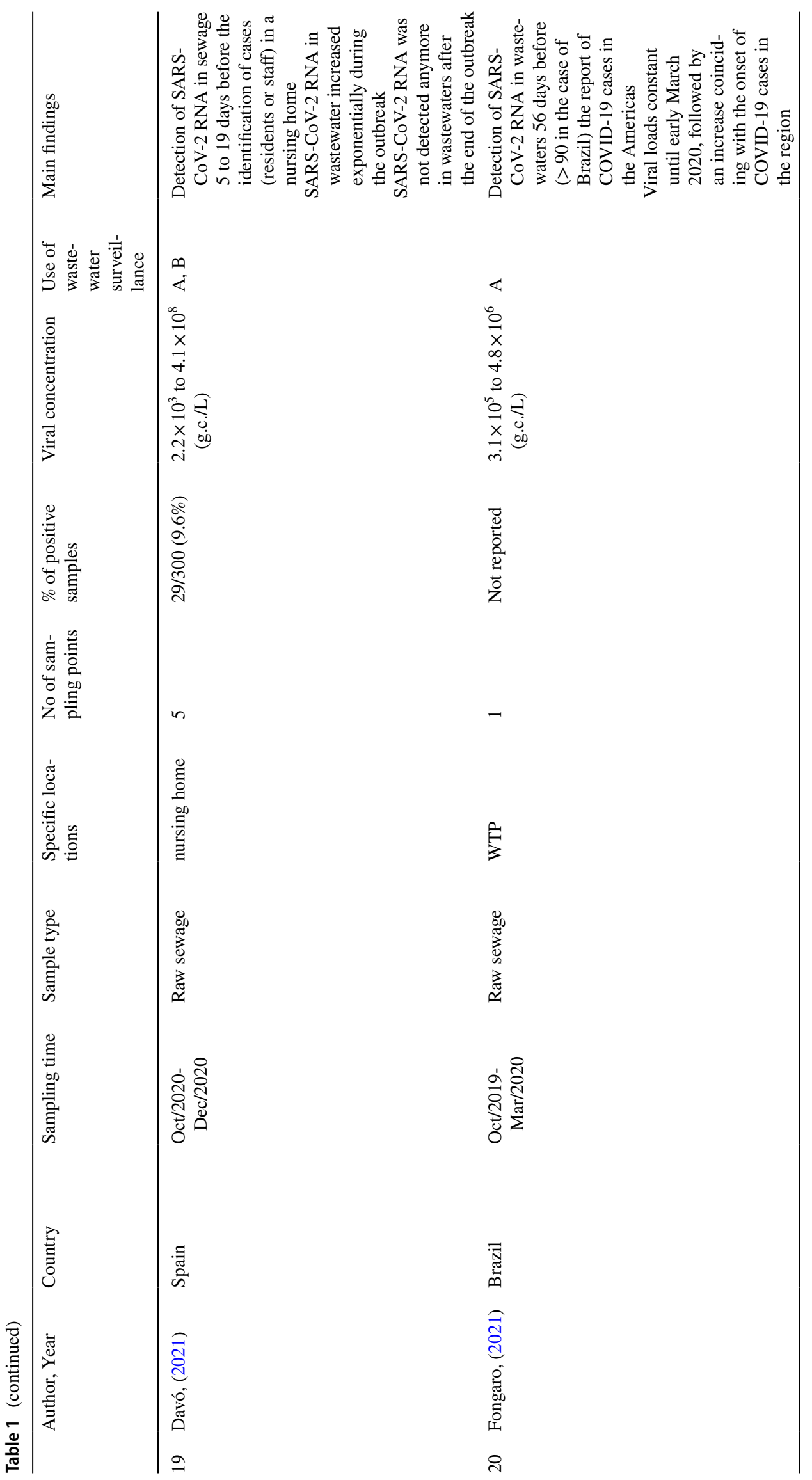




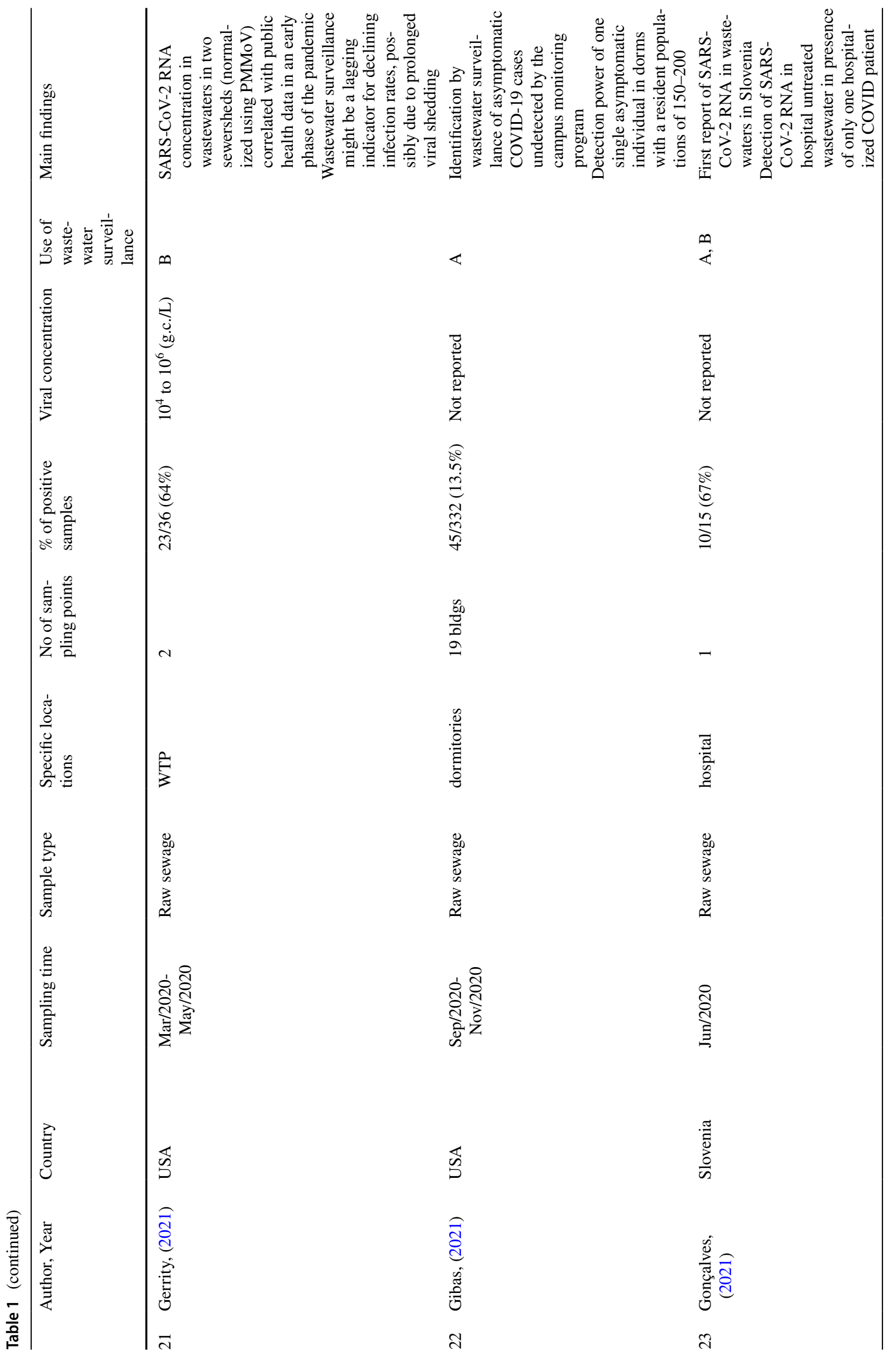




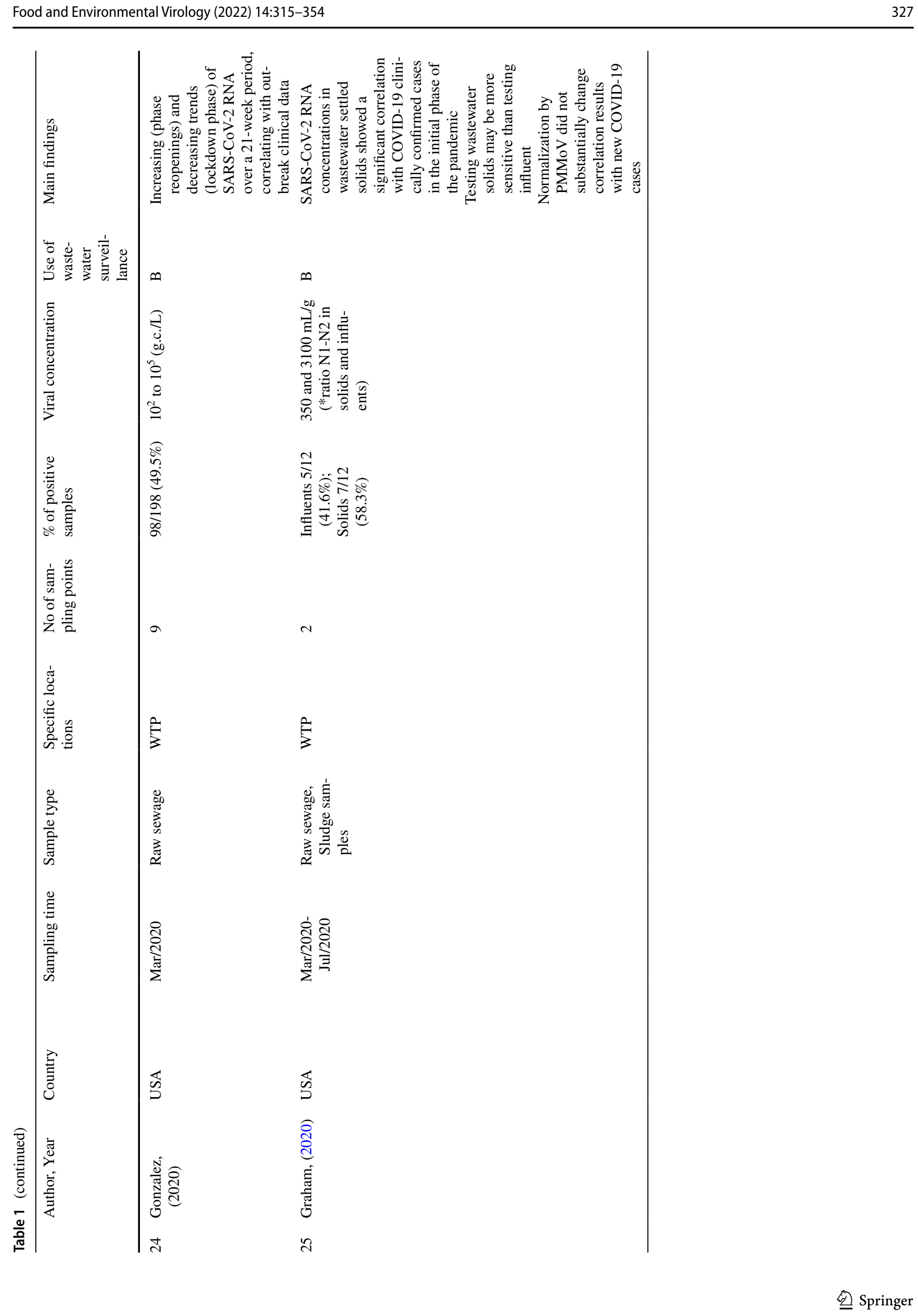




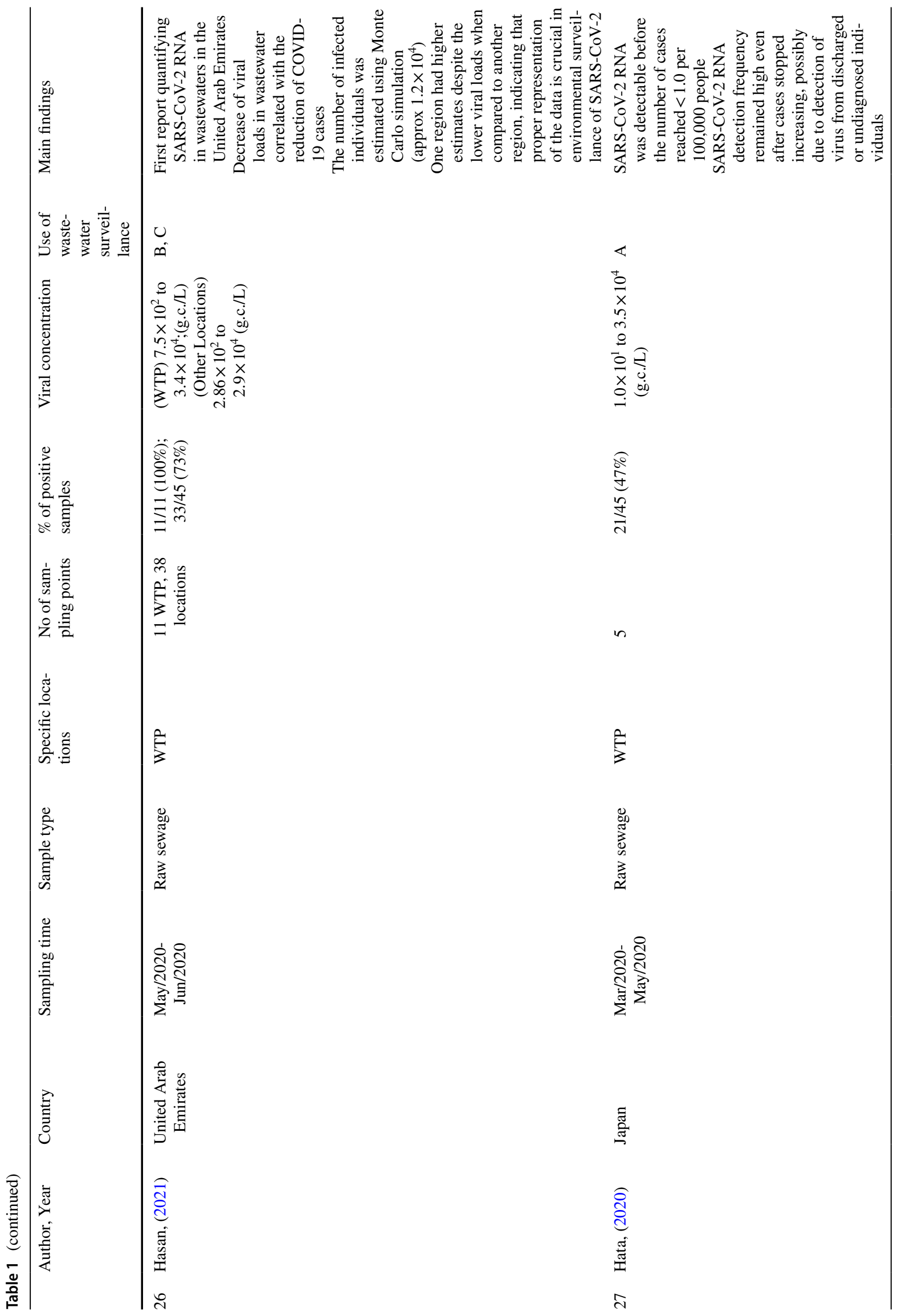




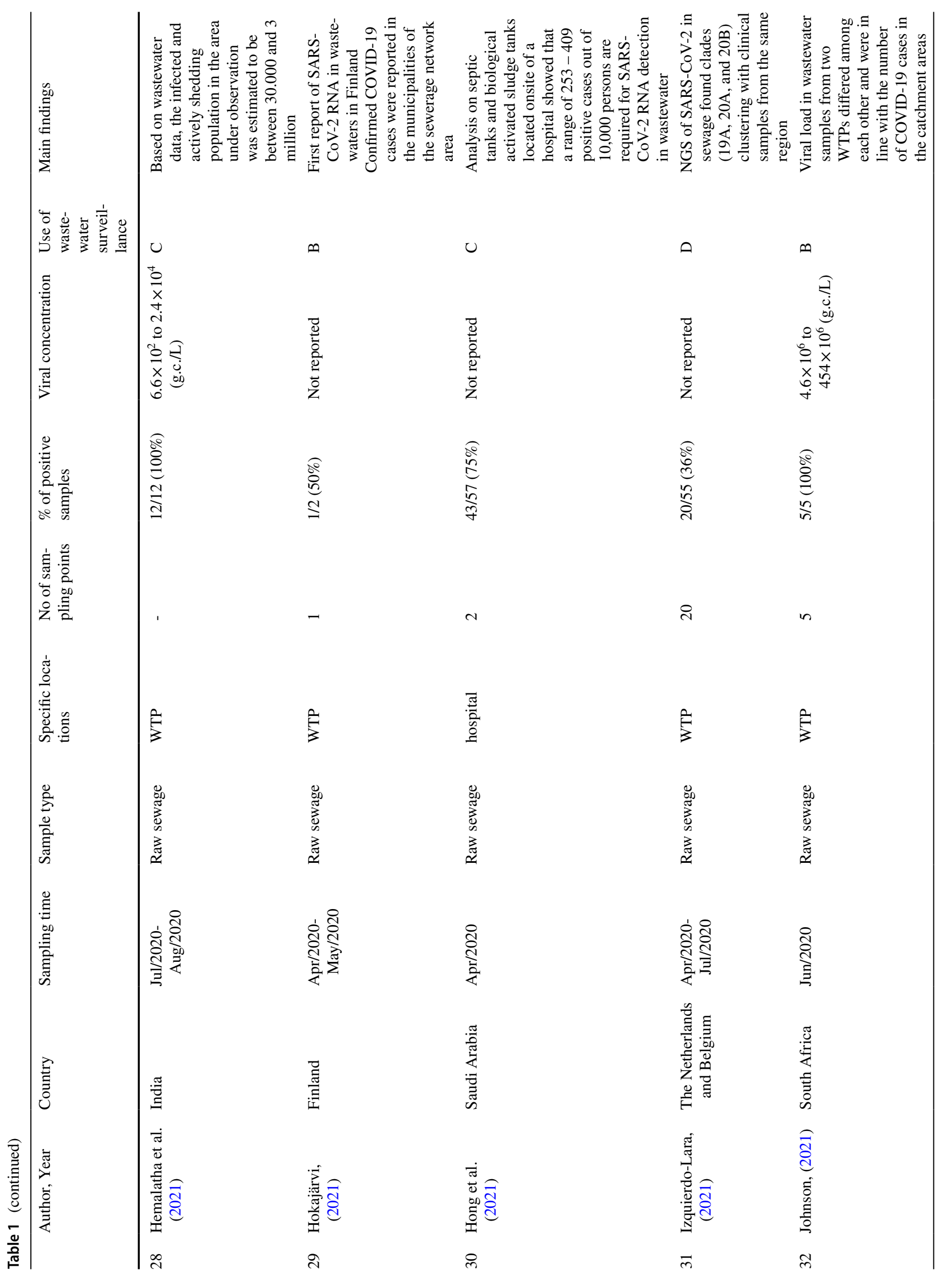




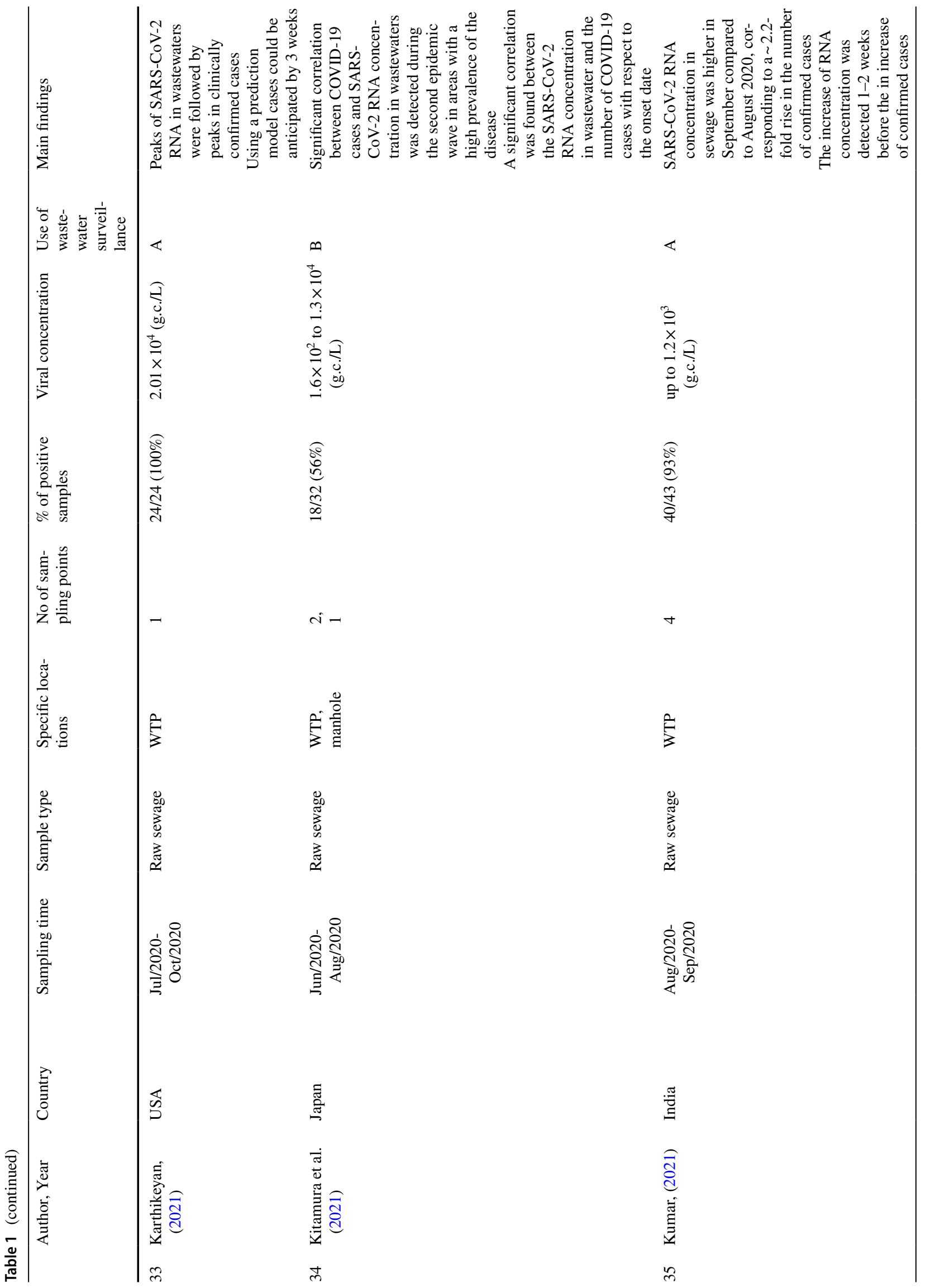




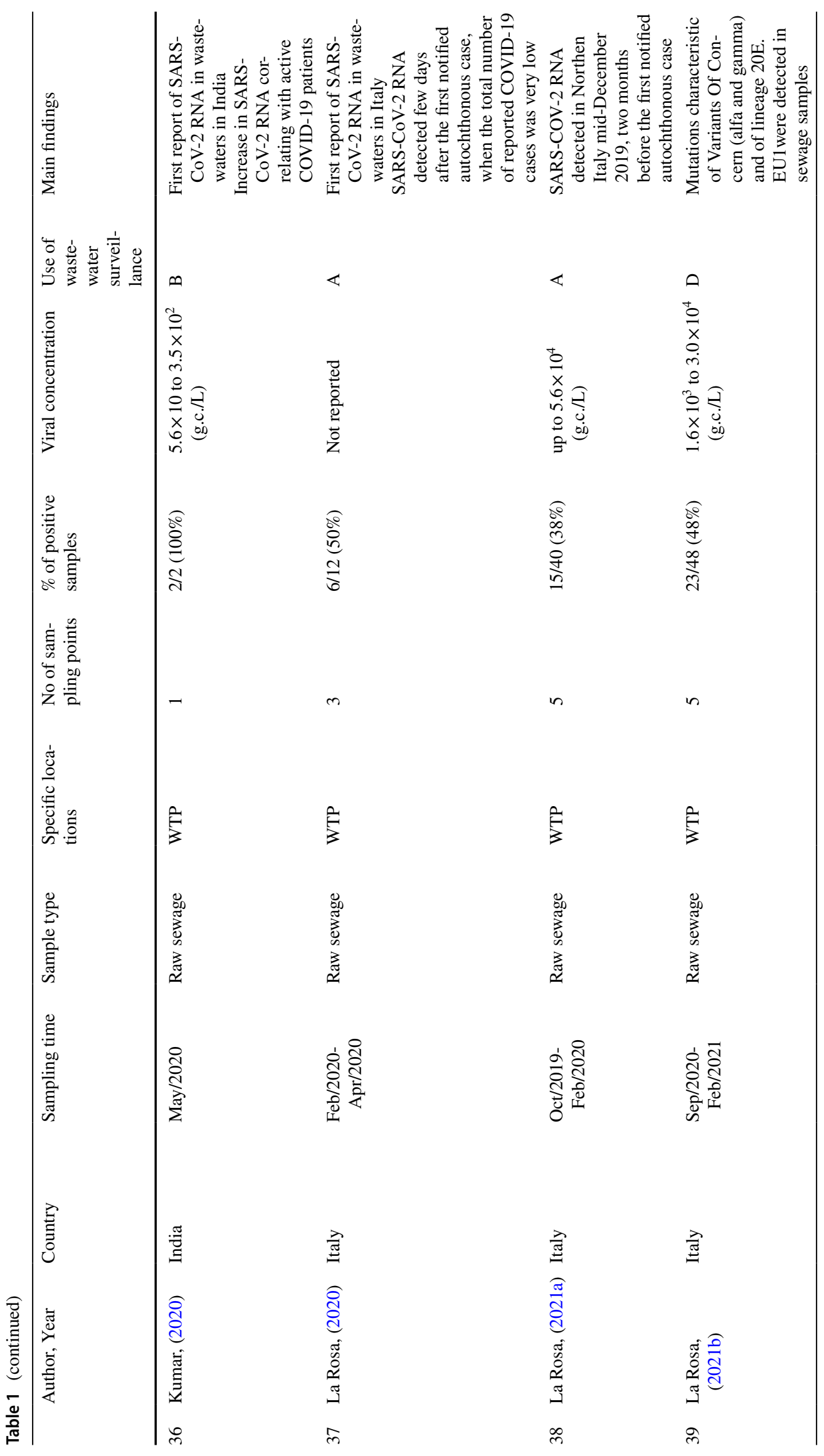




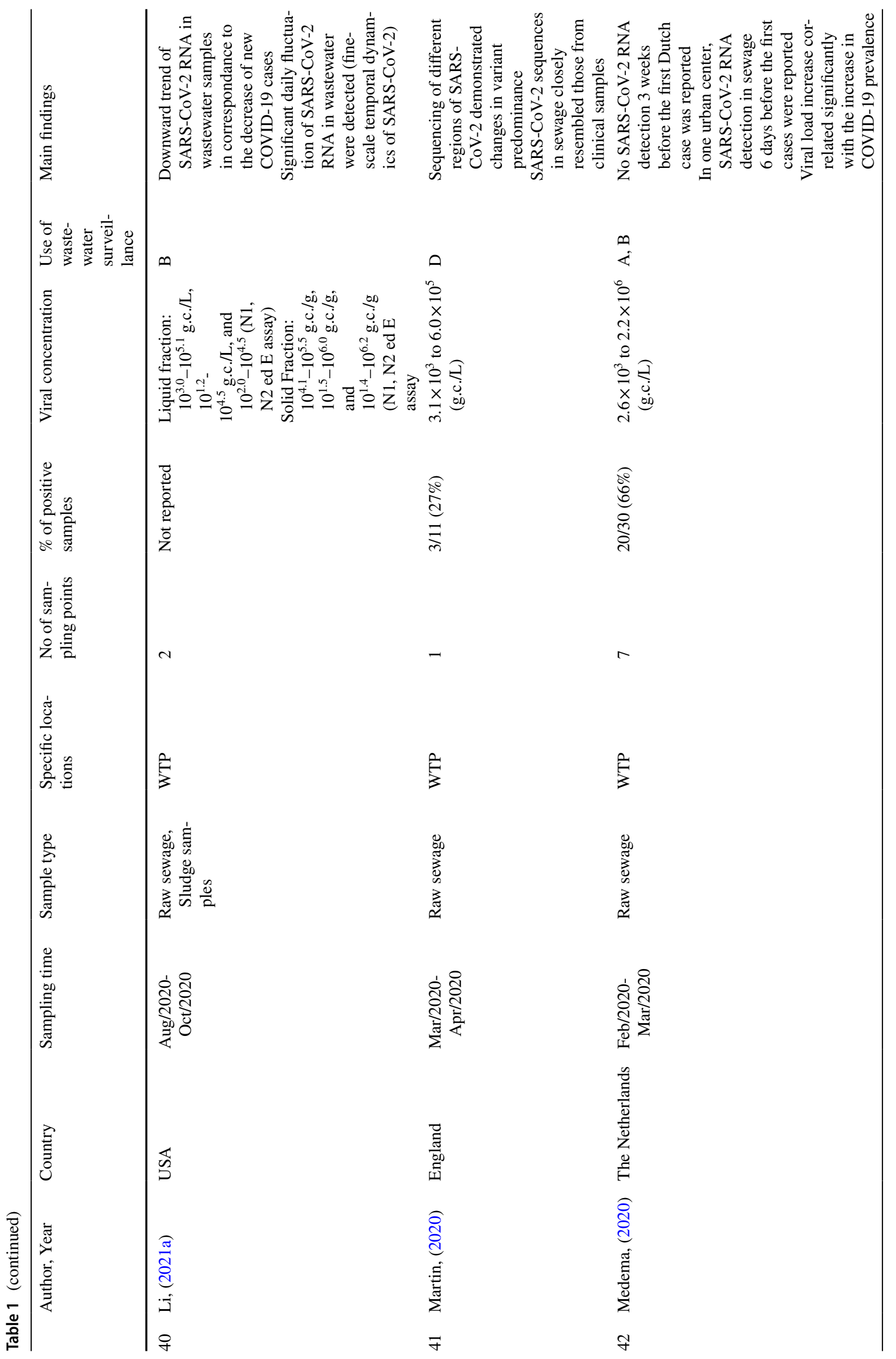




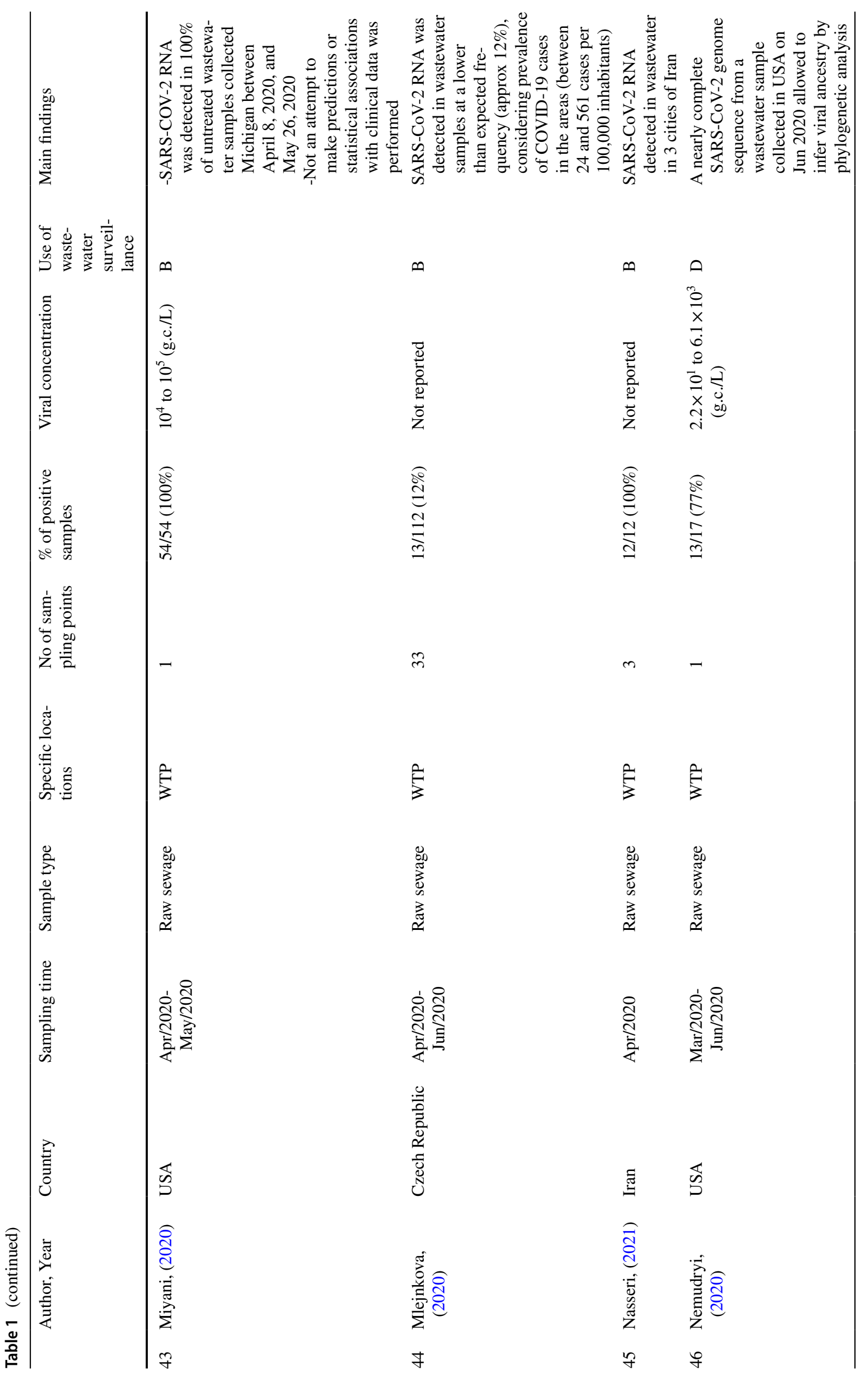




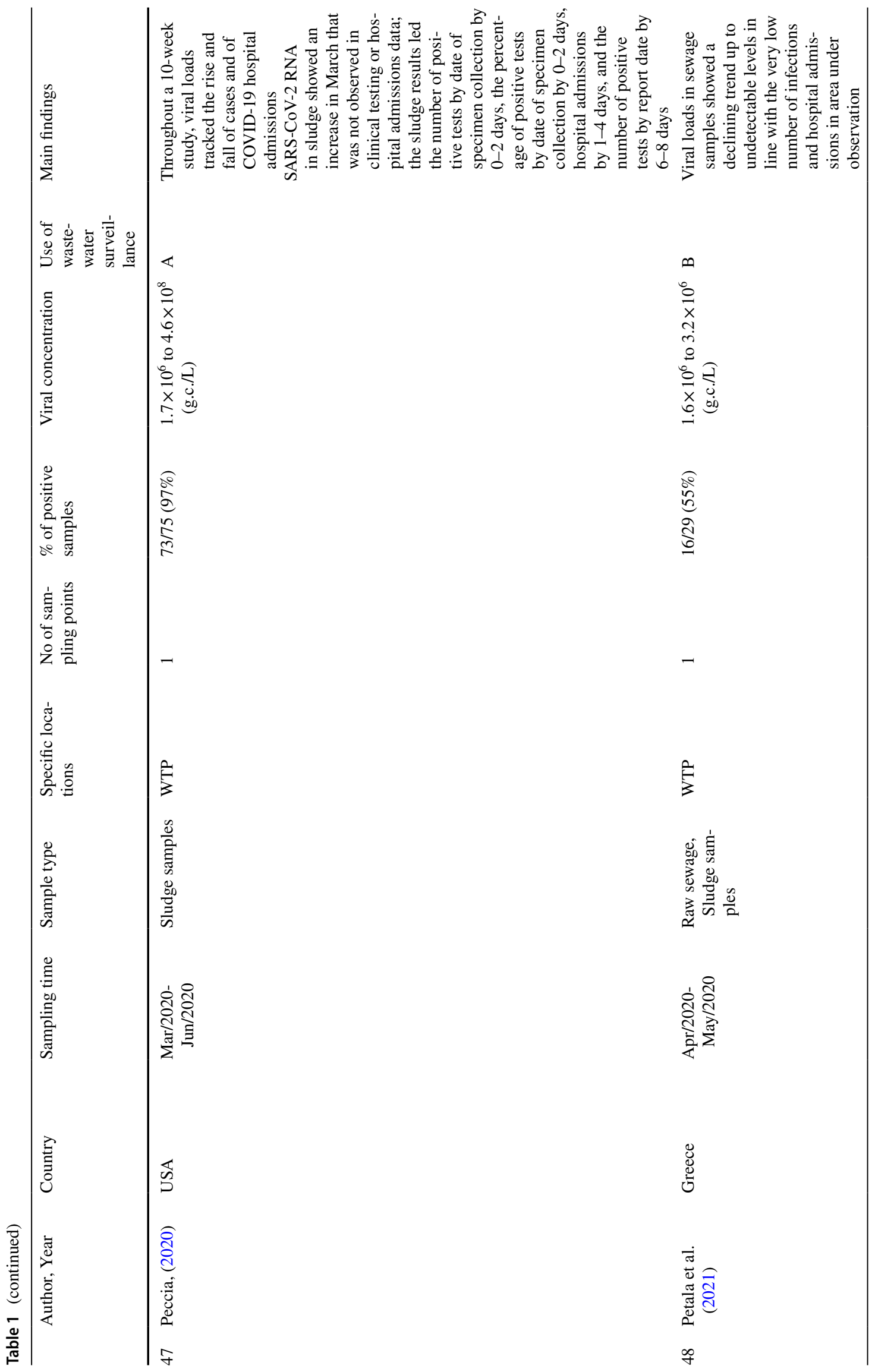




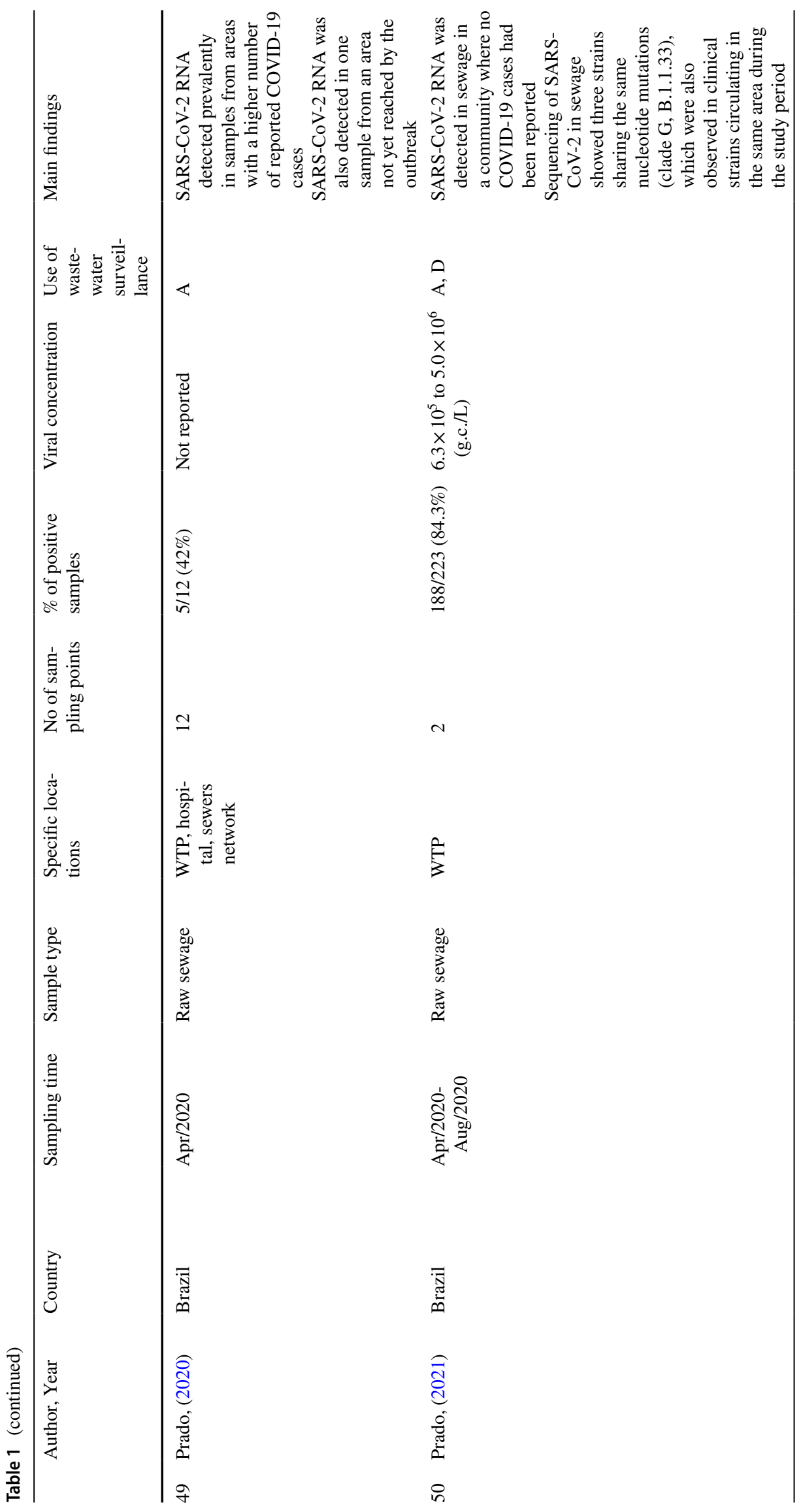




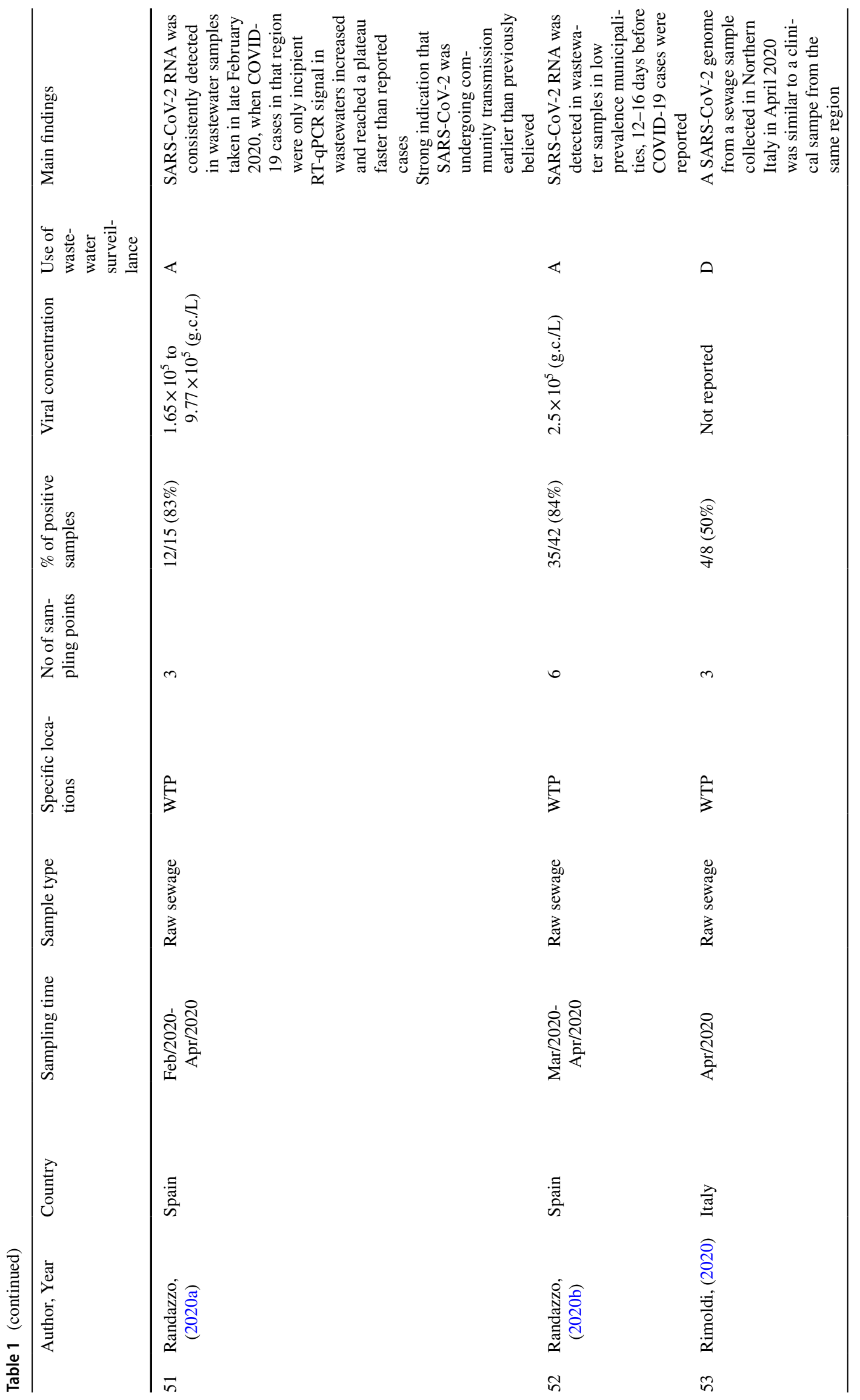




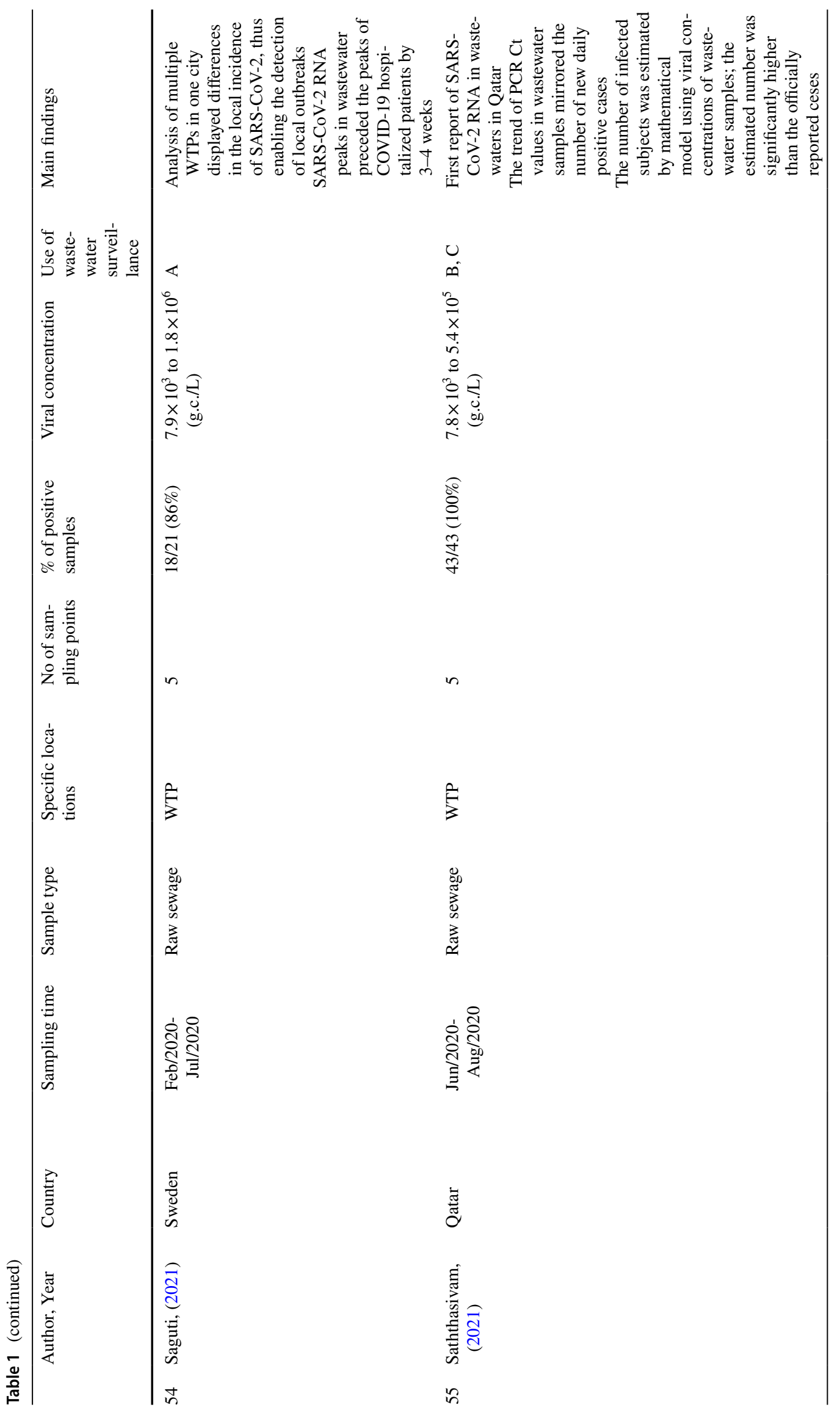




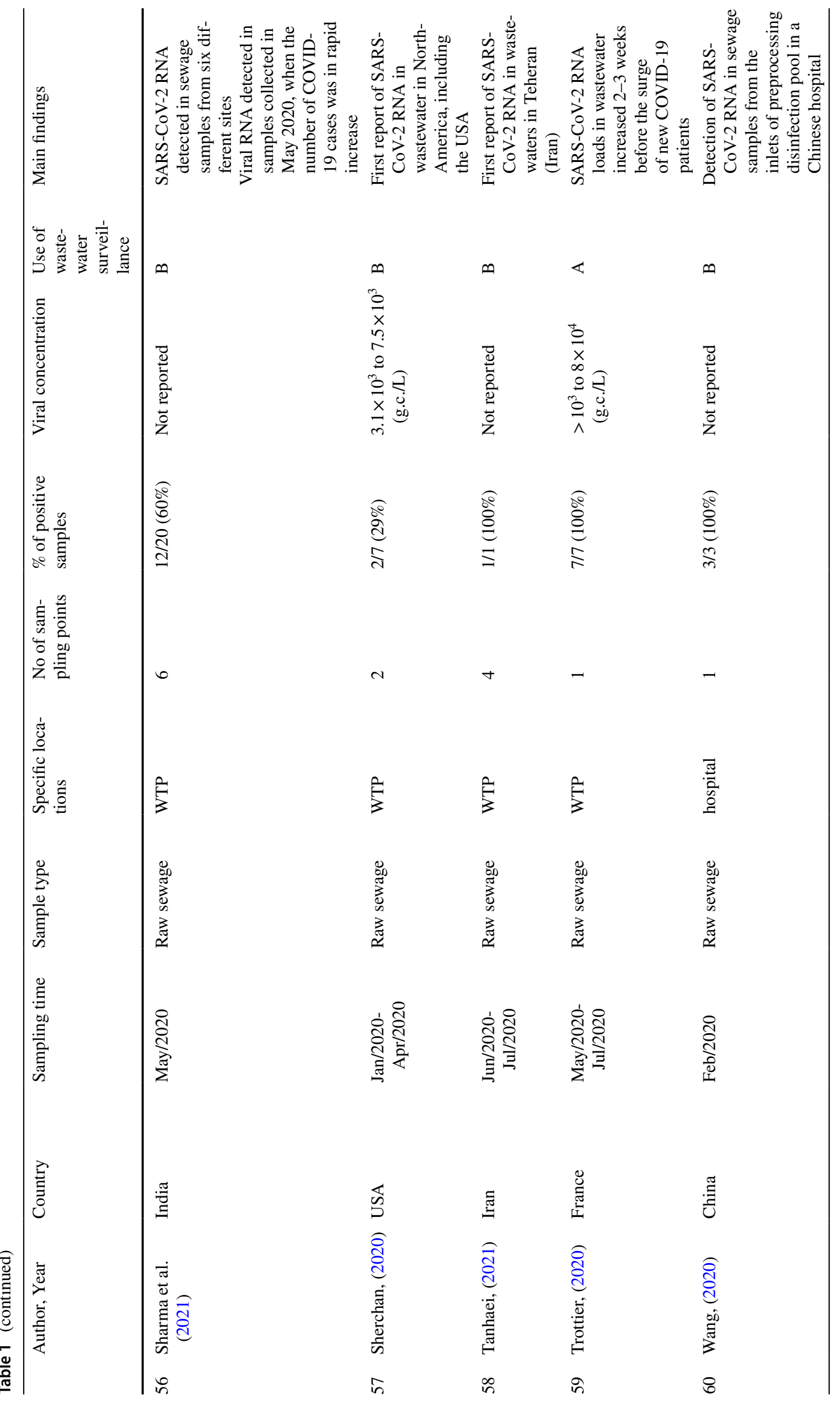




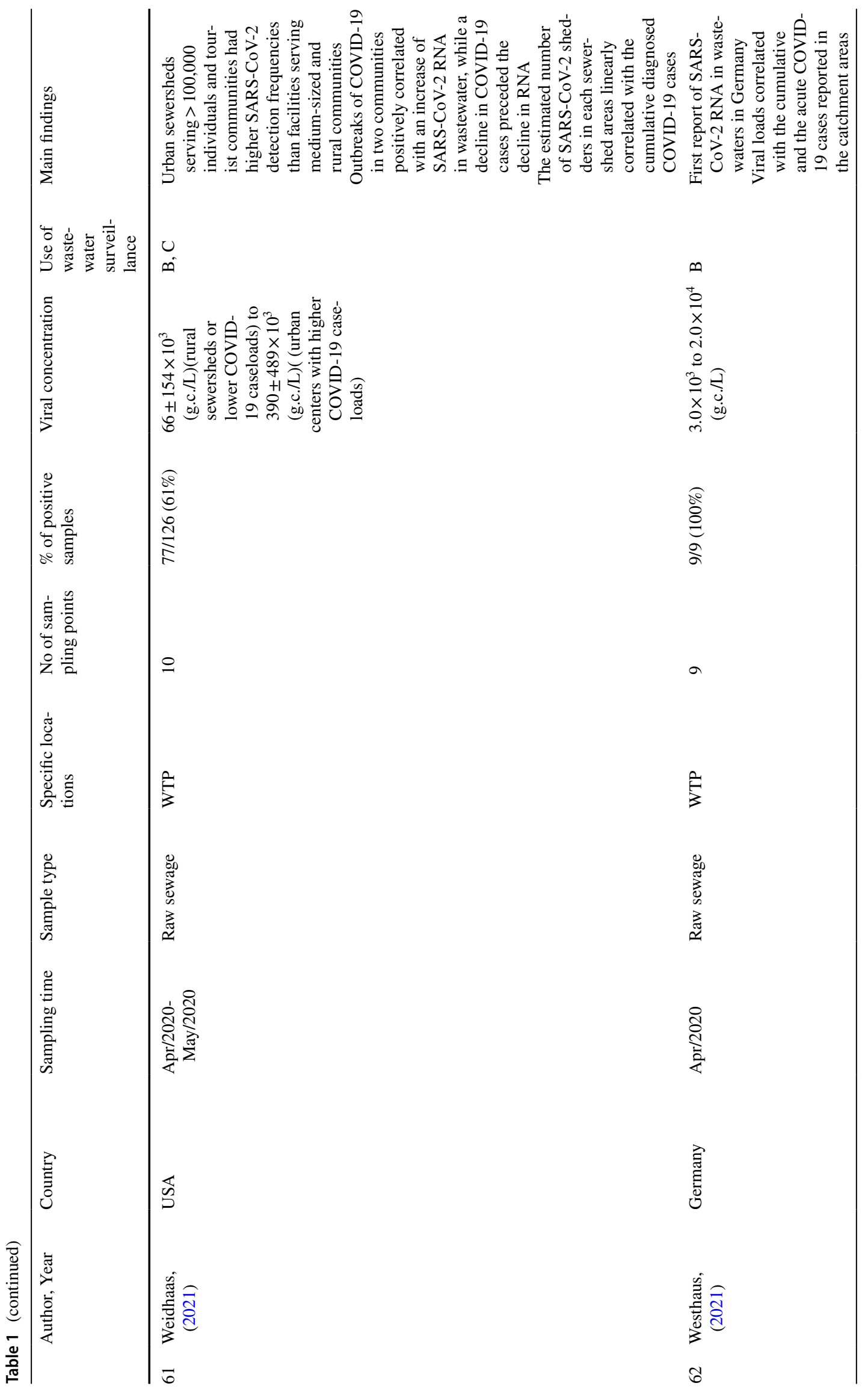




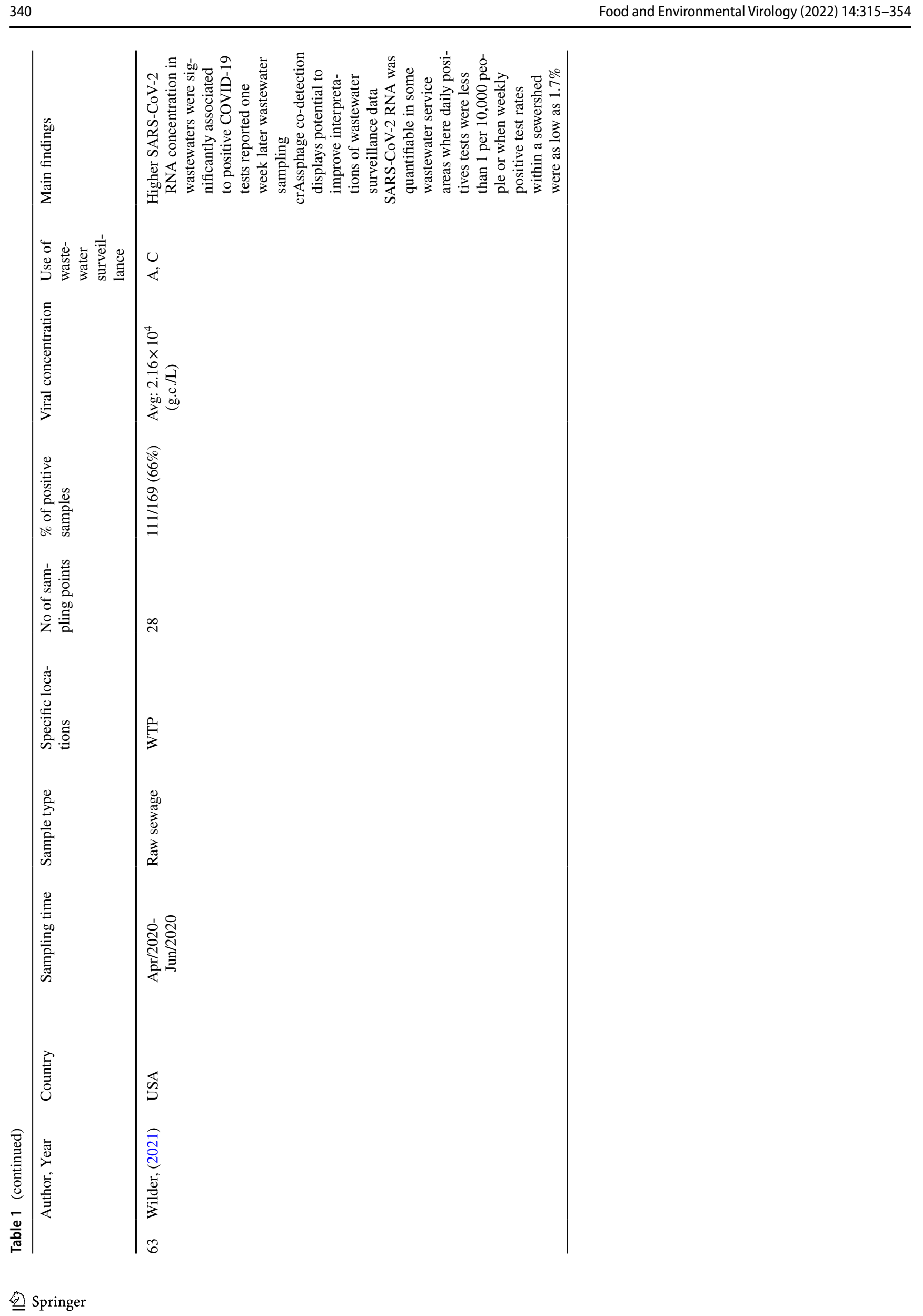




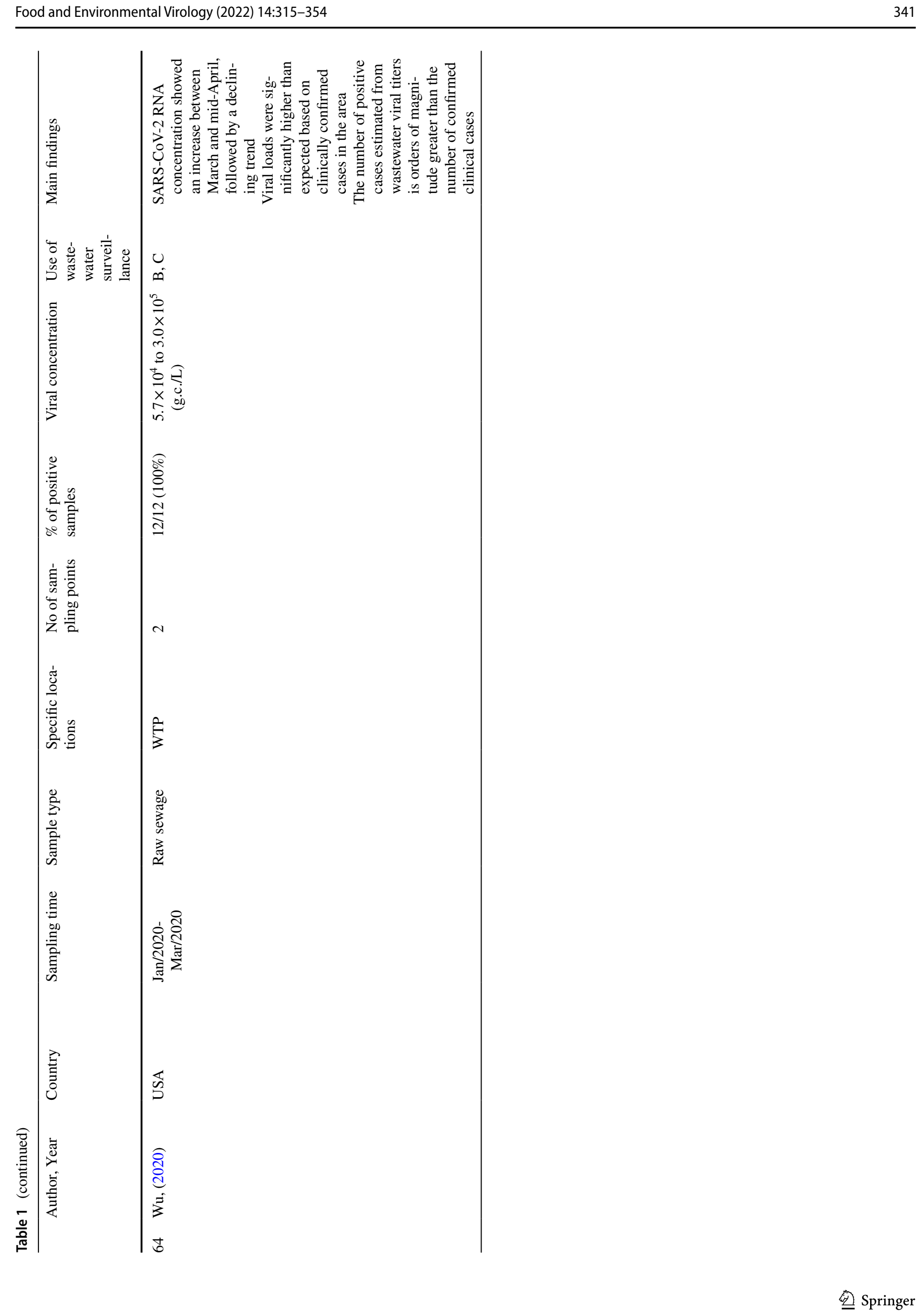




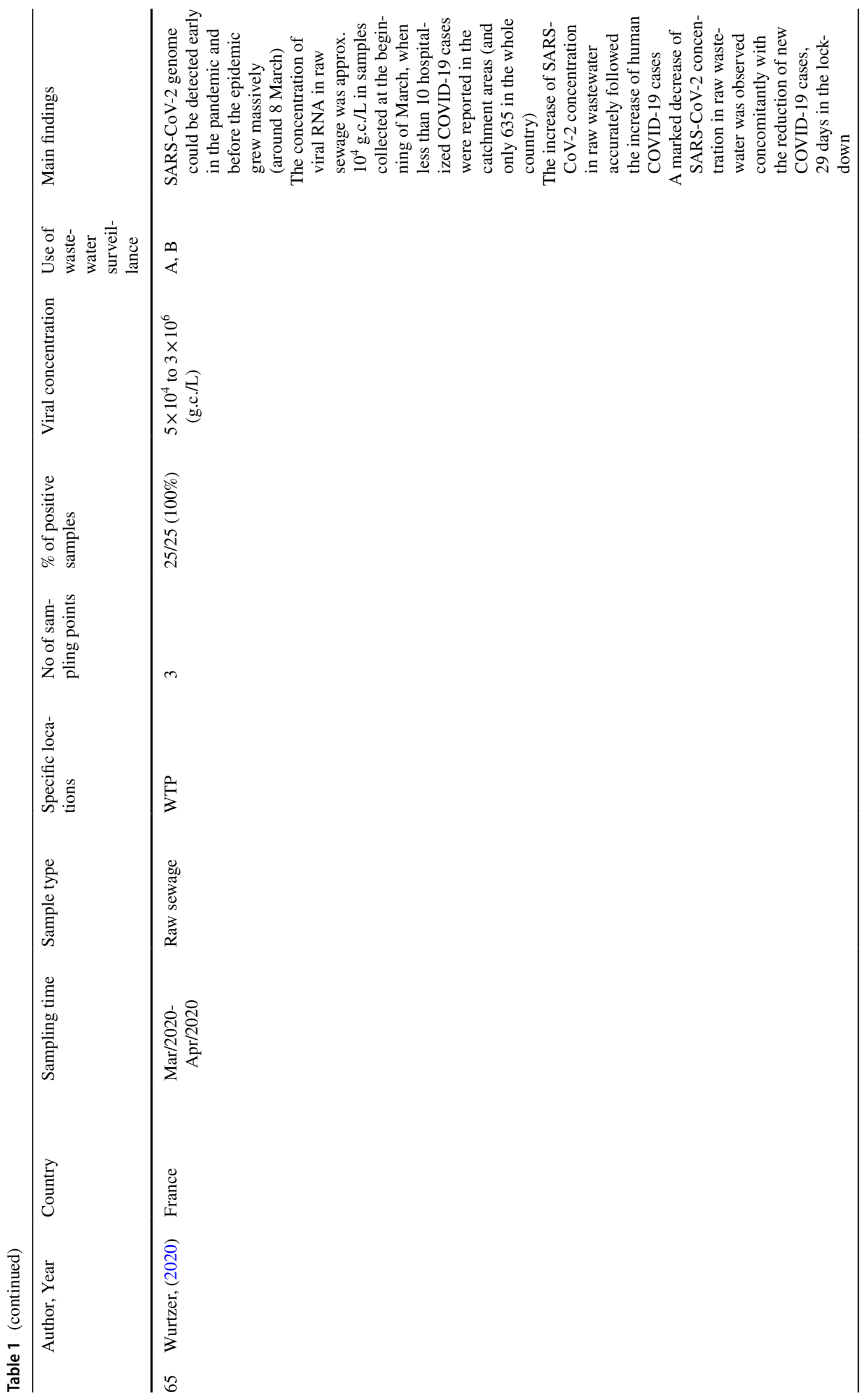




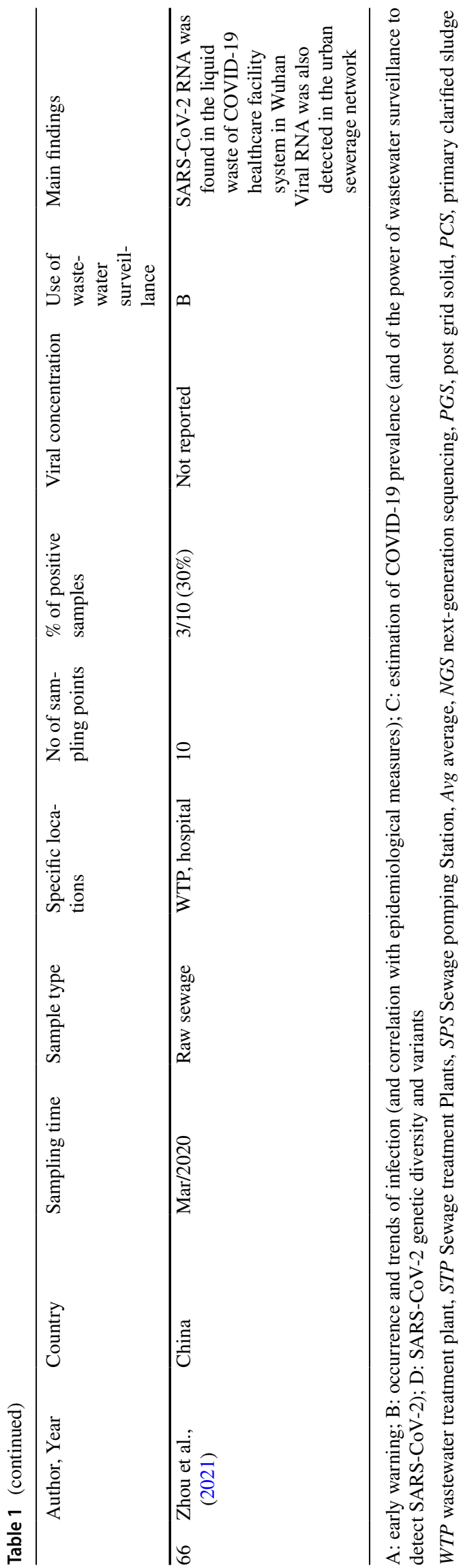

Ottawa, Canada, SARS-CoV-2 was detected in sewage during the summer of 2020, when clinical testing recorded daily percent positivity below $1 \%$ (D'Aoust et al., 2021a). Finally, in The Netherlands, virus RNA was detected in sewage when the COVID-19 prevalence was still low (Medema et al., 2020).

iii. Increment of SARS-CoV-2 RNA in the wastewater before rise in clinical COVID-19 cases.

Seven studies reported viral concentrations increasing days or weeks ahead of positive test results: two days before in the City of Ottawa, Canada (D'Aoust et al., 2021b), one/two weeks ahead in Connecticut, US (Peccia et al., 2020), in New York (Wilder et al., 2021), in India (Kumar et al., 2021), and in Frankfurt, Germany (Agrawal et al., 2021a), and roughly 2-3 weeks in the Montpellier area in France (Trottier et al., 2020). Finally, in San Diego, California, a model showed that environmental surveillance data could predict one-week COVID-19 cases with excellent accuracy, and 3-week cases with fair accuracy (Karthikeyan et al., 2021).

iv. Increment of SARS-CoV-2 RNA in the wastewater before rise in local hospital admissions.

Three studies documented an increase in viral concentrations days or weeks ahead of local hospital admissions or increase in hospitalization: 1-4 days ahead in Connecticut, USA (Peccia et al., 2020), four days in the City of Ottawa, Canada (D'Aoust et al., 2021a) and three to four weeks in the city of Gothenburg and surrounding municipalities in Sweden (Saguti et al., 2021). In France, SARS-CoV-2 genome could be detected in wastewater samples during the months of March and April 2020, at a time when less than 10 hospitalized COVID-19 cases were reported in the catchment areas of the studied WWTPs (Wurtzer et al., 2020).

v. Early warning system in congregate living settings.

All the studies described above were based on the analysis of raw sewage or sludge samples collected at WWTPs, and thus representing large communities. Other papers have addressed the usefulness of wastewater surveillance as an early warning system in congregate living settings like university dormitories, college, nursing homes, and hospitals.

In the USA, the results of wastewater samples collected from college dormitory complexes were highly consistent with known presence or absence of COVID-19 cases detected by clinical testing (Colosi et al., 2021). In a University campus in Arizona, the detection of virus RNA in wastewater led to selected clinical testing, resulting in the identification and isolation of infected individuals (both symptomatic and asymptomatic); subsequently, positive wastewater samples 
provided early warning of the presence of infections in a number of dorms, averting potential disease transmission (Betancourt et al., 2021). In another American university campus in North Carolina sewage surveillance allowed the identification of asymptomatic COVID-19 cases not detected by clinical monitoring programs, including in-house contact tracing, symptomatic testing, scheduled testing of student athletes, and daily symptom reporting (Gibas et al., 2021).

Wastewater surveillance applied to nursing homes in Valencia, Spain, detected SARS-CoV-2 infection cases. Moreover, the presence of SARS-CoV-2 RNA in sewage preceded the identification of cases among residents and staff or outbreak declaration, with lag times ranging from 5 to 19 days (Davó et al., 2021). In Slovenia, detection of SARS-CoV-2 RNA in hospital wastewater from an area with low COVID-19 prevalence was reported at a time in which only one patient was hospitalized (Gonçalves et al., 2021).

\section{Wastewater Surveillance to Assess Infection Occurrence and Trends, and its Correlation with Epidemiological Measures}

i. Assessing SARS-COV-2 occurrence and trends in large communities

Thirty-five studies reported the importance of SARSCoV-2 detection in the environment as a tool to monitor the spread of the virus in the community (Agrawal et al., 2021a, Ahmed et al., 2021a, Ahmed et al., 2021b, Ahmed et al., 2020a, Albastaki et al., 2021, Arora et al., 2020, Bertrand et al., 2021, Carrillo-Reyes et al., 2021, D'Aoust et al. 2021a, Davó et al., 2021, Gerrity et al., 2021, Gonçalves et al., 2021, Gonzalez et al., 2020, Graham et al., 2021, Hasan et al., 2021, Hokajarvi et al., 2021, Johnson et al., 2021, Kitamura et al., 2021, Kumar et al., 2020, Li et al., 2021a, Medema et al., 2020, Miyani et al., 2020, Mlejnkova et al., 2020, Nasseri et al., 2021, Petala et al., 2021, Saththasivam et al., 2021, Sharma et al., 2021, Sherchan et al., 2020, Tanhaei et al., 2021, Wang et al., 2020, Weidhaas et al., 2021, Westhaus 2021, Wu et al., 2020, Wurtzer et al., 2020, Zhou et al., 2021). Some limited their analyses to the presence or absence of the virus in wastewater without attempting to link wastewater data to epidemiological findings. The majority of studies, however, found that SARS-CoV-2 concentration reflected the circulation of the virus in the population and tracked the rise and fall of cases seen in SARS-CoV-2 clinical test results and local COVID-19 hospital admissions.

An increase in SARS-CoV-2 concentrations in sewage correlated significantly with the increase in reported COVID-19 cases or hospital admission in different studies from a number of countries: The Netherland (Medema et al., 2020), Utah (Weidhaas et al., 2021), Southern Nevada (Gerrity et al., 2021), Germany (Westhaus 2021; Agrawal et al., 2021a), Dubai (Albastaki et al., 2021), India (Arora et al.,
2020; Kumar et al., 2020; Sharma et al., 2021), Mexico (Carrillo-Reyes et al., 2021), Japan (Kitamura et al., 2021).

Other studies found that a decrease in SARS-CoV-2 concentrations provided indirect evidence for a reduction in virus transmission, often in response to precautionary measures implemented by the government, including a lockdown, in the following countries: France (Bertrand et al., 2021; Wurtzer et al., 2020), Greece (Petala et al., 2021), Qatar (Saththasivam et al., 2021), Canada (city of Gatineau) (D'Aoust et al. 2021b), United Arab Emirates (Hasan et al., 2021), Hawaii (Li et al., 2021a, 2021b), and Czech Republic (Mlejnkova et al., 2020), Australia (Ahmed et al., 2021a).

Studies performed over long periods of time observed both increasing and decreasing trends, mirroring outbreak trends. In Virginia, surveillance showed an increase prior to lockdown measures, a fall and a plateau before reopenings, and a significant rise starting following reopenings (Gonzalez et al., 2020); in California, SARS-CoV-2 RNA in wastewater settled solids correlated positively and significantly with COVID-19 clinically confirmed case counts, across both rising and falling periods of the epidemiological curve (Graham et al., 2021).

While in general SARS-CoV-2 concentration reflected the circulation of the virus in the population, lack of correlation was also found. For example in Massachusetts observed viral titers in sewage were significantly higher than expected based on clinically confirmed cases (Wu et al., 2020).

Some studied found that while the increase in case counts may occur concurrently or precede the increase in SARSCoV-2 RNA in wastewater, the decline in SARS-CoV-2 RNA in wastewater may lag the decline in case counts (Gerrity et al., 2021; Hata et al., 2021; Weidhaas et al., 2021).

One study performed in South Africa monitored different WWTPs located in different areas in a single collection date, comparing quantitative data with the number of positive COVID-19 cases detected in the areas at the time and found that SARS-CoV-2 virus titers were in line with the number of positive COVID-19 cases reported in the catchment areas (Johnson et al., 2021).

Finally, a few studies reported only on the first detection of SARS-CoV-2 in wastewater in a certain country, without examining correlations with clinical data. These studies were performed in the following countries: Bangladesh (Ahmed et al., 2021b); Finland (Hokajarvi et al., 2021), Michigan (Miyani et al., 2020), and Tehran (Nasseri et al., 2021; Tanhaei et al., 2021).

ii. SARS-CoV-2 occurrence and trends in congregate living settings

Five studies demonstrated the usefulness of wastewater surveillance to study COVID-19 trends in congregate living settings, including nursing home facilities, hospitals, and large transport vessels. 
One study found that RNA levels in wastewater samples collected at nursing home facilities surged exponentially over the course of outbreaks; disappearance of SARS-CoV-2 RNA from sewers, on the other hand, was associated with the control of outbreaks or with the absence of new documented cases following the implementation of adequate measures (Davó et al., 2021).

Detecting SARS-CoV-2 RNA in samples from both aircraft and cruise ship wastewater indicating that surveillance of wastewater from large transport vessels with their own sanitation systems has potential as a complementary source of data to perform clinical testing and contact tracing among disembarking passengers (Ahmed et al., 2020a).

Three studies investigated occurrence and concentrations of SARS-CoV-2 RNA in hospital sewage: in a Chinese hospital in February 2020, when a total of 33 laboratory-confirmed COVID-19 patients were hospitalized in the isolation wards (Wang et al. 2020a), in another medical facilities in China, in early March 2020 (Zhou et al., 2021), and in hospital wastewater from a low COVID-19 disease prevalence area in Slovenia at a time when only one patient was hospitalized (Gonçalves et al., 2021).

\section{Wastewater Surveillance to Estimate the Prevalence of COVID-19 and its Power to Detect SARS-CoV-2 in a Sewershed}

Given the correlations found between wastewater surveillance and clinical data, eleven studies have addressed SARSCoV-2 detection in the environment as a useful tool to estimate the prevalence of SARS-CoV-2 in the community or to study the power of environmental surveillance to detect SARS-CoV-2 in a sewershed (i.e., the minimal number of shedding individuals needed for environmental samples to yield a positive result) (Ahmed et al., 2020b, Baldovin et al., 2021, Chakraborty et al., 2021, Chavarria-Miró et al., 2021, Hasan et al., 2021, Hemalatha et al., 2021, Hong et al., 2021, Saththasivam et al., 2021, Weidhaas et al., 2021, Wilder et al., 2021, Wu et al., 2020).

In Utah, USA, the estimated number of COVID-19 cases in sewersheds (ten WWTPs covering 1.26 M people), was found to be linearly correlated with the cumulative diagnosed COVID-19 cases in a sewershed (Weidhaas et al., 2021). The estimated wastewater SARS-CoV-2 concentration compared to case counts was $0.78: 1$, suggesting that the estimated sum of SARS-CoV-2 shedders is less than the sum of confirmed cases during the study period, possibly due to decay of the RNA signal in wastewater, or inefficiencies in the sample processing method, or to the fact not all COVID-19 individuals shed the virus in feces and the length and duration of shedding vary between individuals (Weidhaas et al., 2021).

On the other hand, the estimated number of infected individuals in the population, declining from $542,313 \pm 51,159$ to $31,181 \pm 3081$ over the course of the sampling period, was significantly higher than the officially reported numbers in Qatar, possibly due to the fact that sewage surveillance captures not only diagnosed, symptomatic cases, but undiagnosed, asymptomatic and paucisymptomatic cases (Saththasivam et al., 2021). Likewise, findings obtained in Massachusetts, USA showed that the number of positive cases estimated from wastewater viral titers collected at a large treatment facility (rough prevalence of $0.1 \%$ to $5 \%$ depending on the estimated average of viral genomes per $\mathrm{ml}$ in stool) were orders of magnitude greater than the number of confirmed clinical cases $(0.026 \%$ confirmed for the state of Massachusetts) (Wu et al., 2020). The authors highlight that this discrepancy could arise from a number of factors, and additional data on viral shedding in stool over the clinical course of the disease in COVID-19 patients may be required to better interpret these findings.

In Spain, too, estimation of the total number of active shedders from SARS-CoV-2 RNA concentrations in wastewater, suggested a high proportion of asymptomatic infected individuals. The study estimated the prevalence of infection in the population to be 2.0-6.5\%. Proportions of around $0.12 \%$ and $0.09 \%$ of the total population were determined to be required for successful detection of SARS-CoV-2 (Chavarria-Miró et al., 2021).

Wilder and co-workers found that SARS-CoV-2 RNA in wastewater was quantifiable in some service areas with daily positive test rates of less than 1 per 10,000 people, or when weekly positive test rates within a sewershed were as low as 1.7\% (Wilder et al., 2021).

The Monte Carlo simulation was employed to estimate the number of infected individuals in a catchment area in Australia. The simulation estimated a median number of infections ranging from 1,090 on 27/3/2020 to 171 on $1 / 4 / 2020$ in the catchment basin (median prevalence of $0.096 \%$ over the six-day surveillance). Estimates were in reasonable agreement with clinical observations (Ahmed et al., 2021a, 2021b).

An Italian study tested a WWTP serving the city of Padua, in northern Italy, and its hospital district, including a dedicated COVID-19 hospital, and estimated the detection power of wastewater surveillance using hospitalization data to be about 1 COVID-19 case per 500 inhabitants (Baldovin et al., 2021).

The number of infected people in different catchment areas was calculated in southern India post lockdown, in September 2020, using the estimated RNA (in gc/L) in wastewater samples, and was in line with the number of actual active COVID-19 cases in the catchment community (3983 vs 3418) (Chakraborty et al., 2021). In this same country, another study conducted from July 2020 toAugust 2020 estimated the spread of SARS-CoV-2 in the city of Hyderabad (nearly 10 million people), indicating that the 
number of infected people might be anywhere between thirty thousand and three million during the study period (Hemalatha et al., 2021); the possible number of infected people was calculated for three different shedding rates within the range $\left(10^{5}, 10^{6}\right.$, and $10^{7}$ copies $/ \mathrm{mL}$ feces), owing to the uncertainty and difference in the number of viral particles excreted by infected individuals.

SARS-CoV-2 in wastewater samples collected from five WWTPs in two prefectures in Japan was more likely to be detected when COVID-19 was prevalent in the catchment area ( $>10$ confirmed cases per 100,000 people), but it was detectable in wastewater even before the number of cases reached 1 per 100,000 people (Hata et al., 2021).

Finally, Hong and co-workers explored the minimal number of positive cases in a community necessary to detect the virus in wastewater by analyzing wastewaters from a septic tank and a biological activated sludge tank located onsite at a hospital. They found that between 253-409 positive cases per 10,000 people are required for SARS-CoV-2 RNA to be detected in wastewater (Hong et al., 2021).

\section{Wastewater surveillance to investigate SARS-CoV-2 diversity and variants in a community}

Eight studies have reported the importance of sequencing environmental SARS-CoV-2 as a tool to determine strains circulating in the community and to study SARS-CoV-2 diversity (Agrawal et al., 2021b; Crits-Christoph et al., 2021; Izquierdo-Lara et al., 2021; La Rosa et al., 2021b; Martin et al., 2020; Nemudryi et al., 2020; Prado et al., 2021; Rimoldi et al., 2020).

The first "full-genome" sequence of SARS-CoV-2 from sewage, assembled using Ion Torrent PGM sequencer, with a mapping-based approach, was performed on a sample collected from a WWTP in northern Italy in April 2020. The phylogenetic analysis revealed that the sequenced strain was closely related to a SARS-CoV-2 strain isolated in the same region in March 2020, and to the commonest strains in Europe (Rimoldi et al., 2020).

In Germany, SARS-CoV-2 RNA from wastewater samples collected in December 2020 were sequenced. The analysis revealed 75 mutations, most of which had been previously reported in clinical samples only outside of Frankfurt, indicating that the sequencing of SARS-CoV-2 RNA in wastewater can provide insights into emerging variants in a city (Agrawal et al., 2021b).

Similar findings were reported by sequencing complete and near-complete SARS-CoV-2 consensus genomes from sewage collected in the San Francisco Bay in July 2020; the major consensus genotypes detected in the sewage were identical to clinical genomes from the region. Additional variants not found in clinical samples, were also identified in wastewaters (Crits-Christoph et al., 2021).
Martin and co-workers demonstrated changes in SARSCoV-2 variant predominance in sewage collected in March/ April 2020, using a nested RT-PCR approach targeting five different regions of the viral genome, concluding that viral RNA sequences found in sewage closely resemble those from clinical samples (Martin et al., 2020).

Genomic surveillance of strains detected in sewage in April/August 2020 in Brazil identified three complete consensus files, obtain by the assembled reads, showing the same nucleotide mutations, all belonging to clade $\mathrm{G}$, B.1.1.33. These mutations had been observed in strains circulating in Rio de Janeiro during the period of the study (Prado et al., 2021).

Nemudryi and co-workers were able to obtain a nearly complete SARS-CoV-2 genome sequence from a wastewater sample collected in the USA in June 2020. Eleven singlenucleotide variants were detected in the assembled genome, which distinguished the wastewater SARS-CoV-2 sequence from the Wuhan-Hu-1/2019 reference sequence (Nemudryi et al., 2020).

Izquierdo-Lara and co-workers used next-generation sequencing of sewage samples to evaluate the diversity of SARS-CoV-2 in the Netherlands and Belgium between April and July 2020, finding the most prevalent clades (19A, 20A, and 20B), and clustering sewage samples with clinical samples from the same region. Several novel mutations in the SARS-CoV-2 genome were also detected (Izquierdo-Lara et al., 2021).

More recently, mutations characteristic of variants of concern (VOCs; Alpha and Gamma variant) and of other variants (20E (EU1)) were found in sewage samples collected in Italy between January and February 2021, using a long nested RT-PCR assay to detect key spike protein mutations distinctive of the major known circulating SARS-CoV-2 variants (La Rosa et al., 2021b).

\section{Discussion}

Environmental virologists have studied pathogens in sewage for decades. In 1946, Dr. Melnick, was the first to point out that the presence or absence of poliovirus in sewage can give not only information on the risk of waterborne transmission, but also epidemiological information (Melnick, 1947). Today, the WHO recognizes the importance of environmental surveillance for poliovirus. It recommends clinical surveillance as a gold standard, but underlines that environmental surveillance can give valuable supplementary information, particularly in urban populations where acute flaccid paralysis surveillance is absent or questionable, persistent virus circulation is suspected, or frequent virus re-introduction is perceived (World Health 2003). Indeed, the discovery of polio transmission in Israel in 2013 through 
sewage monitoring- the first re-emergence in that country since 1988 - provided evidence that sewage monitoring could be used to reveal possible silent transmission globally. Over the last decades, environmental surveillance has been successfully used to study the circulation of a number of other enteric viruses, such as norovirus, adenovirus, hepatitis A and E viruses, and others (La Rosa \& Muscillo, 2013; Sinclair et al., 2008). Moreover, the usefulness of environmental surveillance for viral pathogens has been demonstrated for non-enteric viruses as well - viruses like papillomavirus and polyomavirus (Hamza \& Hamza, 2018; La Rosa et al., 2013).

The analysis of wastewater to monitor the emergence and spread of infectious disease at a population level has received renewed attention in light of the current COVID19 pandemic.

After the first detection of SARS-CoV-2 in wastewaters by Medema and co-workers in the Netherlands (Medema et al., 2020), a number of research groups have started working on monitoring SARS-CoV-2 in sewage. So far, National Wastewater Surveillance Systems have been implemented worldwide in response to the COVID-19 pandemic, in order to help public health officials to better understand the extent of SARS-CoV-2 infections in communities. Examples of European countries with an active WBE Surveillance system and related websites can be found in supplementary Table 3 .

For further information on applicability of SARS-CoV-2 sewage surveillance for supporting public health decisions and actions, see also recent reviews (Amereh et al., 2021; Lundy et al., 2021; McClary-Gutierrez et al., 2021).

The aim of this review was to summarize the state of the art of sewage surveillance applied to SARS-CoV-2, focusing on the main findings in terms of its potential contribution to clinical COVID-19 surveillance and to efforts to control the pandemic.

Studies reviewed here reported the presence of SARS CoV-2 in sewage of different origin in 26 countries, covering practically every continent.

Twenty-five studies have reported the detection of SARS$\mathrm{CoV}-2$ in the environment before the emergence of clinical cases, or a rise of SARS-CoV-2 concentrations in the environment before these same trends became evident in the number of clinical cases or hospitalizations, illustrating the potential of WBE as an early warning system. Some of these studies documented the detection of SARS-CoV-2 RNA in sewage as early as December 2019 (Fongaro et al., 2021; La Rosa et al., 2021a) or in any case before the official notification of cases in the investigated areas (Ahmed 2021a; Chavarria-Miró et al., 2021; Medema et al., 2020; Prado et al., 2020; Randazzo et al., 2020b). Other studies found SARS-CoV-2 RNA in wastewater when COVID-19 cases in that region were incipient and only a limited number of clinical cases had been documented or reported (La Rosa et al.,
2020; Randazzo et al., 2020a; Wurtzer et al., 2020). In one study, viral RNA was detectable even before the number of cases reached $<1.0$ per 100,000 people (Hata et al., 2021).

What is more, different authors demonstrated increases in SARS-CoV-2 viral loads in wastewater anticipating the onset of COVID-19 reported cases or hospitalizations by days or even weeks illustrating the ability of wastewater surveillance to anticipate the onset of subsequent waves (Agrawal et al., 2021a; D'Aoust et al., 2021a; Karthikeyan et al., 2021; Kumar et al., 2021; Peccia et al., 2020; Saguti et al., 2021; Trottier et al., 2020; Wilder et al., 2021).

Some studies have also demonstrated the usefulness of sewage monitoring to provide early warning of infections in buildings, such as universities, dormitories, hospitals or nursing homes (Betancourt et al., 2021; Colosi et al., 2021; Davó et al., 2021; Gibas et al., 2021; Gonçalves et al., 2021), documenting the subsequent interventions taken following the alarm. Near-source tracking in sewers serving particular buildings has emerged as an interesting non-invasive tool that, when combined with subsequent targeted population screening, may enable rapid identification and control of facility outbreaks (Hassard et al., 2021). In general, the early detection of SARS-CoV-2 RNA in wastewater can identify hotspots and sound the alarm in the event of imminent danger, allowing public health officials to coordinate and implement interventions to control the spread of infections.

Thirty-four studies monitored the occurrence and trends of COVID-19. Some of these studies also correlated SARS$\mathrm{CoV}-2$ concentrations with epidemiological metrics, finding positive correlations between viral loads in sewage and COVID-19 cases (daily cases, active cases and percent positive) (Agrawal et al., 2021a, Albastaki et al., 2021, Arora et al., 2020, Bertrand et al., 2021, Carrillo-Reyes et al., 2021, D'Aoust et al. 2021b, Gerrity et al., 2021, Gonzalez et al., 2020, Graham et al., 2021, Hasan et al., 2021, Kitamura et al., 2021, Li et al., 2021a, Medema et al., 2020, Peccia et al., 2020, Petala et al., 2021, Saththasivam et al., 2021, Weidhaas et al., 2021, Westhaus 2021, Wurtzer et al., 2020). Moreover, the disappearance of SARS-CoV-2 RNA from sewage was associated with absence of new documented cases following the implementation of adequate preventive measures (Davó et al., 2021). Interestingly, some of the studies found that while the increase in case counts tends to occur concurrently or precede the increase in SARS-CoV-2 RNA in wastewater, the decline in SARS-CoV-2 RNA in wastewater may lag the decline in case counts, possibly due to prolonged viral shedding (Gerrity et al., 2021; Weidhaas et al., 2021).

At any rate, all these studies demonstrate that the quantitative monitoring of SARS-CoV-2 in raw sewage is a relevant indicator of the evolution of viral circulation in the population linked to a given sewage network. 
About $20 \%$ of the studies included in the present review attempted to estimate the prevalence of COVID-19 in a community (residents of a WWTP's catchment area) using SARS-CoV-2 concentration data, the WWTP's average daily influent flow rate, the size of the population served and correction factors (Ahmed et al., 2020b, Baldovin et al., 2021, Chakraborty et al., 2021, Chavarria-Miró et al., 2021, Hasan et al., 2021, Hemalatha et al., 2021, Hong et al., 2021, Saththasivam et al., 2021, Weidhaas et al., 2021, Westhaus 2021, Wilder et al., 2021, Wu et al., 2020). The results of these studies are very variable, and remain rough estimates. The estimated number of SARS-CoV-2 shedders was found to be linearly correlated with the cumulative number of diagnosed COVID-19 cases in the sewershed of one study, but was significantly higher than the officially reported numbers in another. SARS-CoV-2 RNA in wastewater was quantifiable in some service areas with less than 1 per 10,000 people testing positive daily (Wilder et al., 2021). Current limitations and future prospects for WBE as an approach for the estimation of disease burden are described in a recent review (Bhattacharya et al., 2021). Li et al., 2021a, 2021b reviewed uncertainties in assessing SARS-CoV-2 prevalence by wastewater-based epidemiology (Li et al., 2021b). They divided the estimation process into different steps involving virus shedding, in-sewer transportation, sampling and storage, analysis of SARS-CoV-2 RNA concentrations, and back-estimation, and summarized the uncertainties associated with each step (Li et al., 2021b). They concluded that considerable uncertainties arise due to the methodology and the complexity of various processes involved. The EU Commission Recommendation of 17.3.2021 on a common approach to establish a systematic surveillance of SARSCoV-2 and its variants in wastewaters (EUROPEAN COMMISSION, 2021), also underlines the fact that "wastewater surveillance is a tool to observe trends and not an absolute means to draw conclusions about the prevalence of COVID19 in the population."

The Recommendation also addresses the potential of environmental surveillance to study SARS-CoV-2 variants worldwide. New virus variants are evolving and spreading across the world. Some variants are more transmissible, or have a higher propensity to cause severe disease, and therefore constitute a threat to the response against the virus. Alpha, Beta, Gamma, and Delta (B.1.1.7, B.1.351, P.1, and B.1.617.2 pango lineages, respectively, recently relabelled by the WHO) are the so-called variants of concern for which clear evidence is available indicating a significant impact on transmissibility, severity and/or immunity that is likely to affect the epidemiological situation (European Centre for Disease Prevention and Control 2021). On the other hand, for the so-called variants of interest (VOI), the evidence is still preliminary or uncertain. It is therefore of utmost importance to use all available means to detect variants as soon as possible in order to provide timely and suitable responses. Surveillance of SARS-CoV-2 variants in wastewaters can provide a cost-effective, rapid, and reliable source of information in this respect. The vast majority of papers included in the present review looked at the occurrence and quantity of SARS-CoV-2 in wastewaters, but a few studies also sequenced environmental SARS-CoV-2 in order to determine the strains circulating in the community and to study SARS-CoV-2 genetic diversity (Agrawal et al., 2021b; Crits-Christoph et al., 2021; Izquierdo-Lara et al., 2021; La Rosa et al., 2021b; Martin et al., 2020; Nemudryi et al., 2020; Prado et al., 2021; Rimoldi et al., 2020). Some of these studies provided insights into emerging variants in the areas investigated, seeing that sequences yet to be identified in clinical samples, were found in wastewaters. Also, SARS-CoV-2 VOCs have been detected in sewage (pango lineage B.1.1.7 and P.1), suggesting that tracking SARS-CoV-2 variants and their abundance in sewersheds could provide an early warning system for the emergence or spread of more infectious or virulent strains in the community. More recently, SARS-CoV-2 VOCs and VOIs were identified in wastewater samples matching those found in clinical isolates from the same time periods (Ai et al., 2021; Avgeris et al., 2021; Carcereny et al., 2021; Gregory et al., 2021; Heijnen et al., 2021; La Rosa et al., 2021c; Lee et al., 2021; Mishra et al., 2021; Rios et al., 2021; Swift et al., 2021; Wurtz et al., 2021; Yaniv et al., 2021).

Notably, some of the studies reviewed here demonstrated that the data on SARS-CoV-2 environmental monitoring were effectively used to guide public health decisions (Ahmed 2020b, Betancourt et al., 2021; Chavarria-Miró et al., 2021; Gibas et al., 2021; Prado et al., 2021; Saguti et al., 2021). For example, sewer monitoring of SARS-CoV-2 in Spain enabled the identification of specific COVID-19 hot spots and the rapid adoption of appropriate infection control measures, such as mass testing (Chavarria-Miró et al., 2021). In Sweden, an analysis of wastewater from different parts of the city of Gothenburg showing differences in local incidence of SARS-CoV-2 proved useful in the adoption of public health measures such as tracking to mitigate the spread, and in the planning of hospital bed availability and care needs (Saguti et al., 2021). In Brazil, environmental surveillance provided helped identify regions with unreported cases of the disease, mainly in socially vulnerable communities, and define regionalized coping strategies in priority areas and plan the distribution of tests and other resources (Prado et al., 2021). Based on sewage findings, an active surveillance was launched to search for individuals showing COVID-19-related symptoms, infected individuals were identified through testing and measures to control the spread of the disease were implemented. Similarly, Ahmed and co-workers showed that wastewater surveillance in large transport vessels with their own sanitation systems 
(aircraft and cruise ships) has potential as a complementary source of data to prioritize clinical testing and contact tracing among disembarking passengers (Ahmed et al., 2020b). Implementing building-level SARS-CoV-2 wastewater surveillance on a university campus enabled the identification of asymptomatic COVID-19 cases that were not detected by other components of the campus monitoring program (including in-house contact tracing, symptomatic testing, scheduled testing of student athletes, and daily symptom reporting). These findings were delivered to decision makers, who imposed lockdown and testing measures to control the spread of infection (Gibas et al., 2021).The University of Arizona utilized sewage surveillance paired with clinical testing as a surveillance tool to monitor the community for SARS-CoV-2 in near real time, as students re-entered campus in the fall, and identified one symptomatic and two asymptomatic individuals in a dorm, which was critical to COVID-19 containment (Betancourt et al., 2021).

In conclusion, SARS-CoV-2 was detected in wastewater before the first reported clinical cases in many countries, suggesting that monitoring of SARS-CoV-2 in wastewater could serve as an early warning system to identify signs of outbreaks and potentially prevent them in both large and small communities. Monitoring trends in viral concentrations in sewage make it possible to follow the spread and dynamics of the disease, thus allowing the implementation of timely response measures for the containment of outbreaks and wastewater-based epidemiology seems a promising approach for estimating population-wide COVID-19 prevalence. To date, however, uncertainties limit the reliability of this approach. Finally, tracking SARS-CoV-2 variants and their abundance in sewersheds could provide an early warning system for the emergence and/or spread of more infectious or virulent strains in the community.

Supplementary Information The online version contains supplementary material available at https://doi.org/10.1007/s12560-021-09498-6.

\section{References}

Agrawal, S., Orschler, L., \& Lackner, S. (2021a). Long-term monitoring of SARS-CoV-2 RNA in wastewater of the Frankfurt metropolitan area in Southern Germany. Scientific Reports, 11(1), 5372. https://doi.org/10.1038/s41598-021-84914-2

Agrawal, S., Orschler, L., \& Lackner, S. (2021b). Metatranscriptomic Analysis Reveals SARS-CoV-2 mutations in wastewater of the frankfurt metropolitan area in Southern Germany. Microbiol Resour Announc. https://doi.org/10.1128/MRA.00280-21

Ahmed, W., Tscharke, B., Bertsch, P. M., Bibby, K., Bivins, A., Choi, P., Clarke, L., Dwyer, J., Edson, J., Nguyen, T. M. H., O’Brien, J. W., Simpson, S. L., Sherman, P., Thomas, K. V., Verhagen, R., Zaugg, J., \& Mueller, J. F. (2021a). SARS-CoV-2 RNA monitoring in wastewater as a potential early warning system for COVID-19 transmission in the community: A temporal case study. The Science of the Total Environment, 761, 144216.
Ahmed, F., Islam, M. A., Kumar, M., Hossain, M., Bhattacharya, P., Islam, M. T., Hossen, F., Hossain, M. S., Islam, M. S., Uddin, M. M., Islam, M. N., Bahadur, N. M., Didar-Ul-Alam, M., Reza, H. M., \& Jakariya, M. (2021b). First detection of SARS-CoV-2 genetic material in the vicinity of COVID-19 isolation Centre in Bangladesh: Variation along the sewer network. The Science of the Total Environment, 776, 145724. https://doi.org/10.1016/j. scitotenv.2021.145724

Ahmed, W., Bertsch, P. M., Angel, N., Bibby, K., Bivins, A., Dierens, L., Edson, J., Ehret, J., Gyawali, P., Hamilton, K. A., Hosegood, I., Hugenholtz, P., Jiang, G., Kitajima, M., Sichani, H. T., Shi, J., Shimko, K. M., Simpson, S. L., Smith, W., ... Mueller, J. F. (2020a). Detection of SARS-CoV-2 RNA in commercial passenger aircraft and cruise ship wastewater: a surveillance tool for assessing the presence of COVID-19 infected travellers. Journal of Travel Medicine, 27(5), 116. https://doi.org/10.1093/jtm/taaa1 16

Ahmed, W., Angel, N., Edson, J., Bibby, K., Bivins, A., O'Brien, J. W., Choi, P. M., Kitajima, M., Simpson, S. L., Li, J., Tscharke, B., Verhagen, R., Smith, W., Zaugg, J., Dierens, L., Hugenholtz, P., Thomas, K. V., \& Mueller, J. F. (2020b). First confirmed detection of SARS-CoV-2 in untreated wastewater in Australia: A proof of concept for the wastewater surveillance of COVID-19 in the community. The Science of the Total Environment, 728, 138764. https://doi.org/10.1016/j.scitotenv.2020.138764

Ai, Y., Davis, A., Jones, D., Lemeshow, S., Tu, H., He, F., Ru, P., Pan, X., Bohrerova, Z., \& Lee, J. (2021). Wastewater SARS-CoV-2 monitoring as a community-level COVID-19 trend tracker and variants in Ohio. United States. Sci Total Environ., 801, 149757. https://doi.org/10.1016/j.scitotenv.2021.149757

Albastaki, A., Naji, M., Lootah, R., Almeheiri, R., Almulla, H., Almarri, I., Alreyami, A., Aden, A., \& Alghafri, R. (2021). First confirmed detection of SARS-COV-2 in untreated municipal and aircraft wastewater in Dubai, UAE: The use of wastewater based epidemiology as an early warning tool to monitor the prevalence of COVID-19. Science of the Total Environment, 760, 143350.

Alberca, G. G. F., Solis-Castro, R. L., Solis-Castro, M. E., \& Alberca, R. W. (2021). Coronavirus disease-2019 and the intestinal tract: An overview. World Journal Gastroenterol, 27(13), 1255-1266.

Amahmid, O., El Guamri, Y., Rakibi, Y., Ouizat, S., Yazidi, M., Razoki, B., Kaid Rassou, K., Asmama, S., Bouhoum, K., \& Belghyti, D. (2021). Occurrence of SARS-CoV-2 in excreta, sewage, and environment: epidemiological significance and potential risks. International Journal of Environmental Health Research. https://doi.org/10.1080/09603123.2021.1901865

Amereh, F., Negahban-Azar, M., Isazadeh, S., Dabiri, H., Masihi, N., Jahangiri-Rad, M., \& Rafiee, M. (2021). Sewage systems surveillance for SARS-CoV-2: identification of knowledge gaps, emerging threats, and future research needs. Pathogens., 10(8), 946. https://doi.org/10.3390/pathogens10080946.PMID:34451 410;PMCID:PMC8402176

Arora, S., Nag, A., Sethi, J., Rajvanshi, J., Saxena, S., Shrivastava, S. K., \& Gupta, A. B. (2020). Sewage surveillance for the presence of SARS-CoV-2 genome as a useful wastewater based epidemiology (WBE) tracking tool in India. Water Science and Technology: A Journal of the International Association on Water Pollution Research, 82(12), 2823-2836. https://doi.org/10.2166/ wst. 2020.540

Avgeris, M., Adamopoulos, P. G., Galani, A., Xagorari, M., Gourgiotis, D., Trougakos, I. P., Voulgaris, N., Dimopoulos, M. A., Thomaidis, N. S., \& Scorilas, A. (2021). Novel Nested-Seq Approach for SARS-CoV-2 Real-time epidemiology and indepth mutational profiling in wastewater. International Journal of Molecular Sciences, 22(16), 8498. https://doi.org/10.3390/ ijms22168498.PMID:34445204;PMCID:PMC8395163 
Baldovin, T., Amoruso, I., Fonzo, M., Buja, A., Baldo, V., Cocchio, S., \& Bertoncello, C. (2021). SARS-CoV-2 RNA detection and persistence in wastewater samples: An experimental network for COVID-19 environmental surveillance in Padua, Veneto Region (NE Italy). The Science of the Total Environment, 760, 143329. https://doi.org/10.1016/j.scitotenv.2020.143329

Bertrand, I., Challant, J., Jeulin, H., Hartard, C., Mathieu, L., Lopez, S., Scientific Interest Group Obépine, Schvoerer, E., Courtois, S., \& Gantzer, C. (2021). Epidemiological surveillance of SARS$\mathrm{CoV}-2$ by genome quantification in wastewater applied to a city in the northeast of France: Comparison of ultrafiltration- and protein precipitation-based methods. International Journal of Hygiene and Environmental Health, 233, 113692. https://doi. org/10.1016/j.ijheh.2021.113692

Betancourt, W. Q., Schmitz, B. W., Innes, G. K., Prasek, S. M., Pogreba Brown, K. M., Stark, E. R., Foster, A. R., Sprissler, R. S., Harris, D. T., Sherchan, S. P., Gerba, C. P., \& Pepper, I. L. (2021). COVID-19 containment on a college campus via wastewaterbased epidemiology, targeted clinical testing and an intervention. The Science of the Total Environment, 779, 146408. https://doi. org/10.1016/j.scitotenv.2021.146408

Bhattacharya, P., Kumar, M., Islam, M. T., Haque, R., Chakraborty, S., Ahmad, A., Niazi, N. K., Cetecioglu, Z., Nilsson, D., Ijumulana, J., van der Voorn, T., Jakariya, M., Hossain, M., Ahmed, F., Rahman, M., Akter, N., Johnston, D., \& Ahmed, K. M. (2021). Prevalence of SARS-CoV-2 in communities through wastewater surveillance-a potential approach for estimation of disease burden. Current Pollution Reports. https://doi.org/10.1007/ s40726-021-00178-4

Carcereny, A., Martínez-Velázquez, A., Bosch, A., Allende, A., Truchado, P., Cascales, J., Romalde, J. L., Lois, M., Polo, D., Sánchez, G., Pérez-Cataluña, A., Díaz-Reolid, A., Antón, A., Gregori, J., Garcia-Cehic, D., Quer, J., Palau, M., Ruano, C. G., Pintó, R. M., \& Guix, S. (2021). Monitoring Emergence of the SARS-CoV-2 B1.1.7 Variant through the Spanish National SARS-CoV-2 Wastewater Surveillance System (VATar COVID19). Environmental Science and Technology. https://doi.org/10. 1021/acs.est.1c03589

Carrillo-Reyes, J., Barragán-Trinidad, M., \& Buitrón, G. (2021). Surveillance of SARS-CoV-2 in sewage and wastewater treatment plants in Mexico. Journal of Water Process Engineering, 40, 101815 .

Chakraborty, P., Pasupuleti, M., Jai Shankar, M. R., Bharat, G. K., Krishnasamy, S., Dasgupta, S. C., Sarkar, S. K., \& Jones, K. C. (2021). First surveillance of SARS-CoV-2 and organic tracers in community wastewater during post lockdown in Chennai, South India: Methods, occurrence and concurrence. Science of the Total Environment, 778, 146252.

Chavarria-Miró, G., Anfruns-Estrada, E., Martínez-Velázquez, A., Vázquez-Portero, M., Guix, S., Paraira, M., Galofré, B., Sánchez, G., Pintó, R. M., \& Bosch, A. (2021). Time evolution of severe acute respiratory syndrome coronavirus 2 (SARS-CoV-2) in Wastewater during the first pandemic wave of COVID-19 in the Metropolitan Area of Barcelona. Spain. Applied and Environmental Microbiology, 87(7), e02750-e2820. https://doi.org/10. 1128/AEM.02750-20

Colosi, L. M., Barry, K. E., Kotay, S. M., Porter, M. D., Poulter, M. D., Ratliff, C., Simmons, W., Steinberg, L. I., Wilson, D. D., Morse, R., Zmick, P., \& Mathers, A. J. (2021). Development of wastewater pooled surveillance of severe acute respiratory Syndrome Coronavirus 2 (SARS-CoV-2) from Congregate Living Settings. Applied and Environmental Microbiology, 87(13), e0043321. https://doi.org/10.1128/AEM.00433-21

Crits-Christoph, A., Kantor, R. S., Olm, M. R., Whitney, O. N., AlShayeb, B., Lou, Y. C., Flamholz, A., Kennedy, L. C., Greenwald, H., Hinkle, A., Hetzel, J., Spitzer, S., Koble, J., Tan, A.,
Hyde, F., Schroth, G., Kuersten, S., Banfield, J. F., \& Nelson, K. L. (2021). Genome Sequencing of Sewage Detects Regionally Prevalent SARS-CoV-2 Variants. Mbio, 12(1), 2703-2720. https://doi.org/10.1128/mBio.02703-20

D’Aoust, P. M., Graber, T. E., Mercier, E., Montpetit, D., Alexandrov, I., Neault, N., Baig, A. T., Mayne, J., Zhang, X., Alain, T., Servos, M. R., Srikanthan, N., MacKenzie, M., Figeys, D., Manuel, D., Jüni, P., MacKenzie, A. E., \& Delatolla, R. (2021a). Catching a resurgence: Increase in SARS-CoV-2 viral RNA identified in wastewater $48 \mathrm{~h}$ before COVID-19 clinical tests and $96 \mathrm{~h}$ before hospitalizations. The Science of the Total Environment, 770, 145319. https://doi.org/10.1016/j.scitotenv.2021.145319

D’Aoust, P. M., Mercier, E., Montpetit, D., Jia, J. J., Alexandrov, I., Neault, N., Baig, A. T., Mayne, J., Zhang, X., Alain, T., Langlois, M. A., Servos, M. R., MacKenzie, M., Figeys, D., MacKenzie, A. E., Graber, T. E., \& Delatolla, R. (2021b). Quantitative analysis of SARS-CoV-2 RNA from wastewater solids in communities with low COVID-19 incidence and prevalence. Water Research, 188, 116560. https://doi.org/10.1016/j.watres.2020.116560

Davó, L., Seguí, R., Botija, P., Beltrán, M. J., Albert, E., Torres, I., López-Fernández, P. Á., Ortí, R., Maestre, J. F., Sánchez, G., \& Navarro, D. (2021). Early detection of SARS-CoV-2 infection cases or outbreaks at nursing homes by targeted wastewater tracking. Clinical Microbiology and Infection : the Official Publication of the European Society of Clinical Microbiology and Infectious Diseases, 27(7), 1061-1063. https://doi.org/10.1016/j. cmi.2021.02.003

Dergham, J., Delerce, J., Bedotto, M., La Scola, B., \& Moal, V. (2021). Isolation of Viable SARS-CoV-2 virus from feces of an immunocompromised patient suggesting a possible fecal mode of transmission. Journal of Clinical Medicine, 10(12), 2696. https://doi. org/10.3390/jcm10122696.PMID:34207314;PMCID:PMC82 35306

European Centre for Disease Prevention and Control (2021). SARS$\mathrm{CoV}-2$ variants of concern as of 24 June 2021.

European Commission (2021) Commission RECOMMENDATION of 17.3.2021 on a common approach to establish a systematic surveillance of SARS-CoV-2 and its variants in wastewaters in the EU.

Foladori, P., Cutrupi, F., Segata, N., Manara, S., Pinto, F., Malpei, F., Bruni, L., \& La Rosa, G. (2020). SARS-CoV-2 from faeces to wastewater treatment: What do we know? A review. The Science of the Total Environment, 743, 140444. https://doi.org/10.1016/j. scitotenv.2020.140444

Fongaro, G., Stoco, P. H., Souza, D., Grisard, E. C., Magri, M. E., Rogovski, P., Schörner, M. A., Barazzetti, F. H., Christoff, A. P., de Oliveira, L., Bazzo, M. L., Wagner, G., Hernández, M., \& Rodríguez-Lázaro, D. (2021). The presence of SARS-CoV-2 RNA in human sewage in Santa Catarina, Brazil, November 2019. The Science of the Total Environment, 778, 146198. https:// doi.org/10.1016/j.scitotenv.2021.146198

Gerrity, D., Papp, K., Stoker, M., Sims, A., \& Frehner, W. (2021). Early-pandemic wastewater surveillance of SARS-CoV-2 in Southern Nevada: Methodology, occurrence, and incidence/ prevalence considerations. Water Research $X$. https://doi.org/ 10.1016/j.wroa.2020.100086

Gibas, C., Lambirth, K., Mittal, N., Juel, M., Barua, V. B., Roppolo Brazell, L., Hinton, K., Lontai, J., Stark, N., Young, I., Quach, C., Russ, M., Kauer, J., Nicolosi, B., Chen, D., Akella, S., Tang, W., Schlueter, J., \& Munir, M. (2021). Implementing building-level SARS-CoV-2 wastewater surveillance on a university campus. The Science of the Total Environment, 782, 146749. https://doi. org/10.1016/j.scitotenv.2021.146749

Gonçalves, J., Koritnik, T., Mioč, V., Trkov, M., Bolješič, M., Berginc, N., Prosenc, K., Kotar, T., \& Paragi, M. (2021). Detection of SARS-CoV-2 RNA in hospital wastewater from a low 
COVID-19 disease prevalence area. The Science of the Total Environment, 755(Pt 2), 143226. https://doi.org/10.1016/j.scito tenv.2020.143226

Gonzalez, R., Curtis, K., Bivins, A., Bibby, K., Weir, M. H., Yetka, K., Thompson, H., Keeling, D., Mitchell, J., \& Gonzalez, D. (2020). COVID-19 surveillance in Southeastern Virginia using wastewater-based epidemiology. Water Research, 186, 116296. https://doi.org/10.1016/j.watres.2020.116296

Graham, K. E., Loeb, S. K., Wolfe, M. K., Catoe, D., Sinnott-Armstrong, N., Kim, S., Yamahara, K. M., Sassoubre, L. M., Mendoza Grijalva, L. M., Roldan-Hernandez, L., Langenfeld, K., Wigginton, K. R., \& Boehm, A. B. (2021). SARS-CoV-2 RNA in Wastewater Settled Solids Is Associated with COVID-19 Cases in a Large Urban Sewershed. Environmental Science \& Technology, 55(1), 488-498. https://doi.org/10.1021/acs.est.0c06191

Greenhalgh, T., Jimenez, J. L., Prather, K. A., Tufekci, Z., Fisman, D., \& Schooley, R. (2021). Ten scientific reasons in support of airborne transmission of SARS-CoV-2. Lancet (london, England), 397(10285), 1603-1605. https://doi.org/10.1016/S01406736(21)00869-2

Gregory, D. A., Wieberg, C. G., Wenzel, J., Lin, C. H., \& Johnson, M. C. (2021). Monitoring SARS-CoV-2 populations in wastewater by amplicon sequencing and using the Novel Program SAM Refiner. Viruses, 13(8), 1647. https://doi.org/10.3390/v1308 1647.PMID:34452511;PMCID:PMC8402658

Guo, M., Tao, W., Flavell, R. A., \& Zhu, S. (2021). Potential intestinal infection and faecal-oral transmission of SARS-CoV-2. Nature Reviews. Gastroenterology \& Hepatology, 18(4), 269-283. https://doi.org/10.1038/s41575-021-00416-6

Hamza, H., \& Hamza, I. A. (2018). Oncogenic papillomavirus and polyomavirus in urban sewage in Egypt. The Science of the Total Environment, 610-611, 1413-1420. https://doi.org/10.1016/j. scitotenv.2017.08.218

Hasan, S. W., Ibrahim, Y., Daou, M., Kannout, H., Jan, N., Lopes, A., Alsafar, H., \& Yousef, A. F. (2021). Detection and quantification of SARS-CoV-2 RNA in wastewater and treated effluents: Surveillance of COVID-19 epidemic in the United Arab Emirates. Science of the Total Environment, 764, 1429.

Hassard, F., Lundy, L., Singer, A. C., Grimsley, J., \& Di Cesare, M. (2021). Innovation in wastewater near-source tracking for rapid identification of COVID-19 in schools. The Lancet. Microbe, 2(1), e4-e5. https://doi.org/10.1016/S2666-5247(20)30193-2

Hata, A., Hara-Yamamura, H., Meuchi, Y., Imai, S., \& Honda, R. (2021). Detection of SARS-CoV-2 in wastewater in Japan during a COVID-19 outbreak. The Science of the Total Environment, 758, 143578. https://doi.org/10.1016/j.scitotenv.2020.143578

Heijnen, L., Elsinga, G., de Graaf, M., Molenkamp, R., Koopmans, M., $\&$ Medema, G. (2021). Droplet digital RT-PCR to detect SARS$\mathrm{CoV}-2$ signature mutations of variants of concern in wastewater. The Science of the Total Environment, 799, 149456. https://doi. org/10.1016/j.scitotenv.2021.149456

Hemalatha, M., Kiran, U., Kuncha, S. K., Kopperi, H., Gokulan, C. G., Mohan, S. V., \& Mishra, R. K. (2021). Surveillance of SARSCoV-2 spread using wastewater-based epidemiology: Comprehensive study. The Science of the Total Environment, 768, 144704. https://doi.org/10.1016/j.scitotenv.2020.144704

Hokajärvi, A. M., Rytkönen, A., Tiwari, A., Kauppinen, A., Oikarinen, S., Lehto, K. M., Kankaanpää, A., Gunnar, T., Al-Hello, H., Blomqvist, S., Miettinen, I. T., Savolainen-Kopra, C., \& Pitkänen, T. (2021). The detection and stability of the SARS-CoV-2 RNA biomarkers in wastewater influent in Helsinki, Finland. The Science of the Total Environment, 770, 145274. https://doi.org/ 10.1016/j.scitotenv.2021.145274

Hong, P. Y., Rachmadi, A. T., Mantilla-Calderon, D., Alkahtani, M., Bashawri, Y. M., Al Qarni, H., O'Reilly, K. M., \& Zhou, J. (2021). Estimating the minimum number of SARS-CoV-2 infected cases needed to detect viral RNA in wastewater: To what extent of the outbreak can surveillance of wastewater tell us? Environmental Research, 195, 110748. https://doi.org/10.1016/j. envres.2021.110748

Izquierdo-Lara, R., Elsinga, G., Heijnen, L., Munnink, B., Schapendonk, C., Nieuwenhuijse, D., Kon, M., Lu, L., Aarestrup, F. M., Lycett, S., Medema, G., Koopmans, M., \& de Graaf, M. (2021). Monitoring SARS-CoV-2 Circulation and diversity through community wastewater sequencing, the Netherlands and Belgium. Emerging Infectious Diseases, 27(5), 1405-1415. https://doi.org/ 10.3201/eid2705.204410

Johnson, R., Muller, C., Ghoor, S., Louw, J., Archer, E., Surujlal-Naicker, S., Berkowitz, N., Volschenk, M., Bröcker, L., Wolfaardt, G., Van der Walt, M., Mutshembele, A. M., Malema, S., Gelderblom, H. C., Muhdluli, M., Gray, G., Mathee, A., \& Street, R. (2021). Qualitative and quantitative detection of SARS-CoV-2 RNA in untreated wastewater in Western Cape Province. South Africa. South African Medical Journal, 111(3), 198-202. https:// doi.org/10.7196/SAMJ.2021.v111i3.15154

Joukar, F., Yaghubi Kalurazi, T., Khoshsorour, M., Taramian, S., Mahfoozi, L., Balou, H. A., Jafarinezhad, A., Pourkazemi, A., Hesni, E., Asgharnezhad, M., Shenagari, M., Jahanzad, I., Naghipour, M., Maroufizadeh, S., \& Mansour-Ghanaei, F. (2021). Persistence of SARS-CoV-2 RNA in the nasopharyngeal, blood, urine, and stool samples of patients with COVID-19: A hospital-based longitudinal study. Virol J., 18(1), 134. https://doi.org/10.1186/ s12985-021-01599-9.PMID:34210325;PMCID:PMC8248752

Karthikeyan, S., Ronquillo, N., Belda-Ferre, P., Alvarado, D., Javidi, T., Longhurst, C. A., \& Knight, R. (2021). High-Throughput Wastewater SARS-CoV-2 detection enables forecasting of community infection dynamics in San Diego County. mSYstems, 6(2), 45-21. https://doi.org/10.1128/mSystems.00045-21

Kitamura, K., Sadamasu, K., Muramatsu, M., \& Yoshida, H. (2021). Efficient detection of SARS-CoV-2 RNA in the solid fraction of wastewater. Science of The Total Environment, 763, 144587. https://doi.org/10.1016/j.scitotenv.2020.144587

Kumar, M., Joshi, M., Patel, A. K., \& Joshi, C. G. (2021). Unravelling the early warning capability of wastewater surveillance for COVID-19: A temporal study on SARS-CoV-2 RNA detection and need for the escalation. Environmental Research, 196, 110946. https://doi.org/10.1016/j.envres.2021.110946

Kumar, M., Patel, A. K., Shah, A. V., Raval, J., Rajpara, N., Joshi, M., \& Joshi, C. G. (2020). First proof of the capability of wastewater surveillance for COVID-19 in India through detection of genetic material of SARS-CoV-2. The Science of the Total Environment, 746, 141326. https://doi.org/10.1016/j.scitotenv.2020.141326

La Rosa, G., Iaconelli, M., Mancini, P., Bonanno Ferraro, G., Veneri, C., Bonadonna, L., Lucentini, L., \& Suffredini, E. (2020). First detection of SARS-CoV-2 in untreated wastewaters in Italy. The Science of the Total Environment, 736, 139652. https://doi.org/ 10.1016/j.scitotenv.2020.139652

La Rosa, G., Mancini, P., Bonanno Ferraro, G., Veneri, C., Iaconelli, M., Bonadonna, L., Lucentini, L., \& Suffredini, E. (2021a). SARS-CoV-2 has been circulating in northern Italy since December 2019: Evidence from environmental monitoring. The Science of the Total Environment, 750, 141711. https://doi.org/10.1016/j. scitotenv.2020.141711

La Rosa, G., Mancini, P., Bonanno Ferraro, G., Veneri, C., Iaconelli, M., Lucentini, L., Bonadonna, L., Brusaferro, S., Brandtner, D., Fasanella, A., Pace, L., Parisi, A., Galante, D., \& Suffredini, E. (2021b). Rapid screening for SARS-CoV-2 variants of concern in clinical and environmental samples using nested RT-PCR assays targeting key mutations of the spike protein. Water Research, 197, 117104. https://doi.org/10.1016/j.watres.2021.117104

La Rosa, G., Brandtner, D., Mancini, P., Veneri, C., Bonanno Ferraro, G., Bonadonna, L., Lucentini, L., \& Suffredini, E. (2021c). 
Key SARS-CoV-2 mutations of Alpha, Gamma and Eta variants detected in urban wastewaters in Italy by long-read amplicon sequencing based on nanopore technology. Water, 13(18), 2503. https://doi.org/10.3390/w13182503

La Rosa, G., Fratini, M., Accardi, L., D’Oro, G., Della Libera, S., Muscillo, M., \& Di Bonito, P. (2013). Mucosal and cutaneous human papillomaviruses detected in raw sewages. PLOS ONE, 8(1), e52391. https://doi.org/10.1371/journal.pone.0052391

La Rosa, G. and Muscillo, M. (2013) Viruses in Food and Water. Cook, N. (ed), pp. 97-125, Woodhead Publishing.

Lee, Wei Lin; Imakaev, Maxim; Armas, Federica; McElroy, Kyle A.; Gu, Xiaoqiong; Duvallet, Claire; Chandra, Franciscus; Chen, Hongjie; Leifels, Mats; Mendola, Samuel; Floyd-O'Sullivan, Róisín; Powell, Morgan M.; Wilson, Shane T.; Berge, Karl L. J.; Lim, Claire Y. J.; Wu, Fuqing; Xiao, Amy; Moniz, Katya H; Ghaeli, Newsha; Matus, Mariana; Thompson, Janelle; Alm, Eric J (2021) Quantitative SARS-CoV-2 Alpha Variant B117 Tracking in Wastewater by Allele-Specific RT-qPCR. Environmental Science \& Technology Letters 8(8): 675-682 Doi: https:// doi.org/10.1021/acs.estlett.1c00375

Li, B., Di, D. Y. W., Saingam, P., Jeon, M. K., \& Yan, T. (2021a). FineScale Temporal Dynamics of SARS-CoV-2 RNA Abundance in Wastewater during A COVID-19 Lockdown. Water Research, 197, 117093. https://doi.org/10.1016/j.watres.2021.117093

Li, X., Zhang, S., Shi, J., Luby, S. P., \& Jiang, G. (2021b). Uncertainties in estimating SARS-CoV-2 prevalence by wastewater-based epidemiology. Chemical Engineering Journal, 415, 129039.

Lodder, W., \& de Roda Husman, A. M. (2020). SARS-CoV-2 in wastewater: Potential health risk, but also data source. Lancet Gastroenterol Hepatol, 5(6), 533-534.

Lundy, L., Fatta-Kassinos, D., Slobodnik, J., Karaolia, P., Cirka, L., Kreuzinger, N., Castiglioni, S., Bijlsma, L., Dulio, V., Deviller, G., Lai, F. Y., Alygizakis, N., Barneo, M., Baz-Lomba, J. A., Béen, F., Cíchová, M., Conde-Pérez, K., Covaci, A., Donner, E., ... Viklander, M. (2021). Making Waves: Collaboration in the time of SARS-CoV-2 - rapid development of an international co-operation and wastewater surveillance database to support public health decision-making. Water Research, 1(199), 117167. https://doi.org/10.1016/j.watres.2021.117167

Martin, J., Klapsa, D., Wilton, T., Zambon, M., Bentley, E., Bujaki, E., Fritzsche, M., Mate, R., \& Majumdar, M. (2020). Tracking SARS-CoV-2 in Sewage: Evidence of Changes in Virus Variant Predominance during COVID-19 Pandemic. Viruses, 12(10), 1144.

McClary-Gutierrez, J. S., Mattioli, M. C., Marcenac, P., Silverman, A. I., Boehm, A. B., Bibby, K., Balliet, M., \& de Los Reyes, F. L. (2021). SARS-CoV-2 Wastewater Surveillance for Public Health Action. Emerging Infectious Diseases, 27(9), 1-8. https://doi.org/ 10.3201/eid2709.210753

Medema, G., Heijnen, L., Elsinga, G., Italiaander, R., \& Brouwer, A. (2020). Presence of SARS-Coronavirus-2 RNA in Sewage and Correlation with Reported COVID-19 Prevalence in the Early Stage of the Epidemic in The Netherlands. Environmental Science \& Technology Letters, 7(7), 511-516.

Melnick, J. L. (1947). Poliomyelitis virus in urban sewage in epidemic and in nonepidemic times. American Journal of Hygiene, 45(2), 240-253. https://doi.org/10.1093/oxfordjournals.aje.a119132

Mishra, S., Mindermann, S., Sharma, M., Whittaker, C., Mellan, T. A., Wilton, T., Klapsa, D., Mate, R., Fritzsche, M., Zambon, M., Ahuja, J., Howes, A., Miscouridou, X., Nason, G. P., Ratmann, O., Semenova, E., Leech, G., Sandkühler, J. F., Rogers-Smith, C., Vollmer, M., COVID-19 Genomics UK (COG-UK) Consortium. (2021). Changing composition of SARS-CoV-2 lineages and rise of Delta variant in England. EClinicalMedicine, 39, 101064. https://doi.org/10.1016/j.eclinm.2021.101064
Miyani, B., Fonoll, X., Norton, J., Mehrotra, A., \& Xagoraraki, I. (2020). SARS-CoV-2 in Detroit Wastewater. Journal of Environmental Engineering, 146(11), 06020004.

Mlejnkova, H., Sovova, K., Vasickova, P., Ocenaskova, V., Jasikova, L., \& Juranova, E. (2020). Preliminary Study of Sars-Cov-2 Occurrence in Wastewater in the Czech Republic. International Journal of Environmental Research and Public Health, 17(15), 5508. https://doi.org/10.3390/ijerph17155508

Mohapatra, S., Menon, N. G., Mohapatra, G., Pisharody, L., Pattnaik, A., Menon, N. G., Bhukya, P. L., Srivastava, M., Singh, M., Barman, M. K., Gin, K. Y., \& Mukherji, S. (2021). The novel SARS-CoV-2 pandemic: Possible environmental transmission, detection, persistence and fate during wastewater and water treatment. The Science of the Total Environment, 765, 142746. https:// doi.org/10.1016/j.scitotenv.2020.142746

Nasseri, S., Yavarian, J., Baghani, A. N., Azad, T. M., Nejati, A., Nabizadeh, R., Hadi, M., Jandaghi, N., Vakili, B., Vaghefi, S., Baghban, M., Yousefi, S., Nazmara, S., \& Alimohammadi, M. (2021). The presence of SARS-CoV-2 in raw and treated wastewater in 3 cities of Iran: Tehran, Qom and Anzali during coronavirus disease 2019 (COVID-19) outbreak. Journal of Environmental Health Science \& Engineering, 19(1), 1-12. https://doi.org/10. 1007/s40201-021-00629-6

Nemudryi, A., Nemudraia, A., Wiegand, T., Surya, K., Buyukyoruk, M., Cicha, C., Vanderwood, K. K., Wilkinson, R., \& Wiedenheft, B. (2020). Temporal Detection and Phylogenetic Assessment of SARS-CoV-2 in Municipal Wastewater. Cell Reports. Medicine, 1(6), 100098. https://doi.org/10.1016/j.xcrm.2020.100098

Nishiura, H., Linton, N. M., \& Akhmetzhanov, A. R. (2020). Serial interval of novel coronavirus (COVID-19) infections. International Journal of Infectious Diseases : IJID : Official Publication of the International Society for Infectious Diseases, 93, 284-286. https://doi.org/10.1016/j.ijid.2020.02.060

Ouzzani, M., Hammady, H., Fedorowicz, Z., \& Elmagarmid, A. (2016). Rayyan-a web and mobile app for systematic reviews. Systematic Reviews, 5(1), 210. https://doi.org/10.1186/s13643-016-0384-4

Peccia, J., Zulli, A., Brackney, D. E., Grubaugh, N. D., Kaplan, E. H., Casanovas-Massana, A., Ko, A. I., Malik, A. A., Wang, D., Wang, M., Warren, J. L., Weinberger, D. M., Arnold, W., \& Omer, S. B. (2020). Measurement of SARS-CoV-2 RNA in wastewater tracks community infection dynamics. Nature Biotechnology, 38(10), 1164-1167. https://doi.org/10.1038/ s41587-020-0684-z

Pedersen, R. M., Tornby, D. S., Bang, L. L., Madsen, L. W., Skov, M. N., Jensen, T. G., Johansen, I. S., \& Andersen, T. E. (2021). Rectally shed SARS-CoV-2 lacks infectivity: Time to rethink faecal-oral transmission? Nature Reviews. Gastroenterology \& Hepatology, 18(9), 669. https://doi.org/10.1038/s41575-02100501-w.PMID:34312524;PMCID:PMC8311632

Petala, M., Dafou, D., Kostoglou, M., Karapantsios, T., Kanata, E., Chatziefstathiou, A., Sakaveli, F., Kotoulas, K., Arsenakis, M., Roilides, E., Sklaviadis, T., Metallidis, S., Papa, A., Stylianidis, E., Papadopoulos, A., \& Papaioannou, N. (2021). A physicochemical model for rationalizing SARS-CoV-2 concentration in sewage Case study: The city of Thessaloniki in Greece. The Science of the Total Environment, 755(1), 142855. https://doi.org/ 10.1016/j.scitotenv.2020.142855

Petrillo, M., Brogna, C., Cristoni, S., Querci, M., Piazza, O., \& Van den Eede, G. (2021). Increase of SARS-CoV-2 RNA load in faecal samples prompts for rethinking of SARS-CoV-2 biology and COVID-19 epidemiology. F100Res., 10, 370. https://doi.org/10. 12688/f1000research.52540.3

Prado, T., Fumian, T. M., Mannarino, C. F., Resende, P. C., Motta, F. C., \& Eppinghaus, A. (2021). Wastewater-based epidemiology as a useful tool to track SARS-CoV-2 and support public 
health policies at municipal level in Brazil. Water Research, 191, 116810. https://doi.org/10.1016/j.watres.2021.116810

Prado, T., Fumian, T. M., Mannarino, C. F., Maranhão, A. G., Siqueira, M. M., \& Miagostovich, M. P. (2020). Preliminary results of SARS-CoV-2 detection in sewerage system in Niterói municipality, Rio de Janeiro. Brazil. Memorias Do Instituto Oswaldo Cruz, 115, e200196. https://doi.org/10.1590/0074-02760200196

Randazzo, W., Cuevas-Ferrando, E., Sanjuán, R., Domingo-Calap, P., \& Sánchez, G. (2020a). Metropolitan wastewater analysis for COVID-19 epidemiological surveillance. International Journal of Hygiene and Environmental Health, 230, 113621. https://doi. org/10.1016/j.ijheh.2020.113621

Randazzo, W., Truchado, P., Cuevas-Ferrando, E., Simón, P., Allende, A., \& Sánchez, G. (2020b). SARS-CoV-2 RNA in wastewater anticipated COVID-19 occurrence in a low prevalence area. Water Research, 181, 115942. https://doi.org/10.1016/j.watres. 2020.115942

Rimoldi, S. G., Stefani, F., Gigantiello, A., Polesello, S., Comandatore, F., Mileto, D., Maresca, M., Longobardi, C., Mancon, A., Romeri, F., Pagani, C., Cappelli, F., Roscioli, C., Moja, L., Gismondo, M. R., \& Salerno, F. (2020). Presence and infectivity of SARS-CoV-2 virus in wastewaters and rivers. The Science of the Total Environment, 744, 140911. https://doi.org/10.1016/j.scito tenv.2020.140911

Rios, G., Lacoux, C., Leclercq, V., Diamant, A., Lebrigand, K., Lazuka, A., Soyeux, E., Lacroix, S., Fassy, J., Couesnon, A., Thiery, R., Mari, B., Pradier, C., Waldmann, R., \& Barbry, P. (2021). Monitoring SARS-CoV-2 variants alterations in Nice neighborhoods by wastewater nanopore sequencing. The Lancet regional health: Europe. https://doi.org/10.1016/j.lanepe.2021.100202

Sinclair, R. G., Choi, C. Y., Riley, M. R., \& Gerba, C. P. (2008). Pathogen surveillance through monitoring of sewer systems. Advances in Applied Microbiology, 65, 249-269. https://doi.org/10.1016/ S0065-2164(08)00609-6.PMID: 19026868;PMCID:PMC71 12011

Ruan, Q., Yang, K., Wang, W., Jiang, L., \& Song, J. (2020). Clinical predictors of mortality due to COVID-19 based on an analysis of data of 150 patients from Wuhan. China. Intensive Care Medicine, 46(5), 846-848. https://doi.org/10.1007/ s00134-020-05991-x

Saawarn, B., \& Hait, S. (2021). Occurrence, fate and removal of SARS$\mathrm{CoV}-2$ in wastewater: Current knowledge and future perspectives. Journal of Environmental Chemical Engineering, 9(1), 104870. https://doi.org/10.1016/j.jece.2020.104870

Saguti, F., Magnil, E., Enache, L., Churqui, M. P., Johansson, A., Lumley, D., Davidsson, F., Dotevall, L., Mattsson, A., Trybala, E., Lagging, M., Lindh, M., Gisslén, M., Brezicka, T., Nyström, K., \& Norder, H. (2021). Surveillance of wastewater revealed peaks of SARS-CoV-2 preceding those of hospitalized patients with COVID-19. Water Research, 189, 116620. https://doi.org/ 10.1016/j.watres.2020.116620

Saththasivam, J., El-Malah, S. S., Gomez, T. A., Jabbar, K. A., Remanan, R., Krishnankutty, A. K., Ogunbiyi, O., Rasool, K., Ashhab, S., Rashkeev, S., Bensaad, M., Ahmed, A. A., Mohamoud, Y. A., Malek, J. A., Abu Raddad, L. J., Jeremijenko, A., Abu Halaweh, H. A., Lawler, J., \& Mahmoud, K. A. (2021). COVID19 (SARS-CoV-2) outbreak monitoring using wastewater-based epidemiology in Qatar. The Science of the Total Environment, 774, 145608. https://doi.org/10.1016/j.scitotenv.2021.145608

Sharma, D. K., Nalavade, U. P., Kalgutkar, K., Gupta, N., \& Deshpande, J. M. (2021). SARS-CoV-2 detection in sewage samples: Standardization of method \& preliminary observations. The Indian Journal of Medical Research, 153(1 \& 2), 159-165. https://doi.org/10.4103/ijmr.IJMR_3541_20

Sherchan, S. P., Shahin, S., Ward, L. M., Tandukar, S., Aw, T. G., Schmitz, B., Ahmed, W., \& Kitajima, M. (2020). First detection of SARS-CoV-2 RNA in wastewater in North America: A study in Louisiana, USA. The Science of the Total Environment, 743, 140621. https://doi.org/10.1016/j.scitotenv.2020.140621

Swift, C. L., Isanovic, M., Correa Velez, K. E., \& Norman, R. S. (2021). Community-level SARS-CoV-2 sequence diversity revealed by wastewater sampling. Science of the Total Environment, 801, 149691. https://doi.org/10.1016/j.scitotenv.2021.149691

Tanhaei, M., Mohebbi, S. R., Hosseini, S. M., Rafieepoor, M., Kazemian, S., Ghaemi, A., Shamloei, S., Mirjalali, H., Asadzadeh Aghdaei, H., \& Zali, M. R. (2021) The first detection of SARS-CoV-2 RNA in the wastewater of Tehran, Iran. Environmental Science and Pollution Research International, https://doi. org/10.1007/s11356-021-13393-9.

Treibel, T. A., Manisty, C., Burton, M., McKnight, Á., Lambourne, J., Augusto, J. B., Couto-Parada, X., Cutino-Moguel, T., Noursadeghi, M., \& Moon, J. C. (2020). COVID-19: PCR screening of asymptomatic health-care workers at London hospital. Lancet (london, England), 395(10237), 1608-1610. https://doi.org/10. 1016/S0140-6736(20)31100-4

Trottier, J., Darques, R., Ait Mouheb, N., Partiot, E., Bakhache, W., Deffieu, M. S., \& Gaudin, R. (2020). Post-lockdown detection of SARS-CoV-2 RNA in the wastewater of Montpellier, France. One Health (amsterdam, Netherlands), 10, 100157. https://doi. org/10.1016/j.onehlt.2020.100157

van Doorn, A. S., Meijer, B., Frampton, C., Barclay, M. L., \& de Boer, N. (2020). Systematic review with meta-analysis: SARS-CoV-2 stool testing and the potential for faecal-oral transmission. Alimentary Pharmacology \& Therapeutics, 52(8), 1276-1288. https://doi.org/10.1111/apt.16036

Wang, J., Feng, H., Zhang, S., Ni, Z., Ni, L., Chen, Y., Zhuo, L., Zhong, Z., \& Qu, T. (2020). SARS-CoV-2 RNA detection of hospital isolation wards hygiene monitoring during the Coronavirus Disease 2019 outbreak in a Chinese hospital. International Journal of Infectious Diseases : IJID : Official Publication of the International Society for Infectious Diseases, 94, 103-106. https://doi. org/10.1016/j.ijid.2020.04.024

Weidhaas, J., Aanderud, Z. T., Roper, D. K., VanDerslice, J., Gaddis, E. B., Ostermiller, J., Hoffman, K., Jamal, R., Heck, P., Zhang, Y., Torgersen, K., Laan, J. V., \& LaCross, N. (2021). Correlation of SARS-CoV-2 RNA in wastewater with COVID-19 disease burden in sewersheds. The Science of the Total Environment, 775, 145790. https://doi.org/10.1016/j.scitotenv.2021.145790

Westhaus, S., Weber, F. A., Schiwy, S., Linnemann, V., Brinkmann, M., Widera, M., Greve, C., Janke, A., Hollert, H., Wintgens, T., \& Ciesek, S. (2021). Detection of SARS-CoV-2 in raw and treated wastewater in Germany - Suitability for COVID-19 surveillance and potential transmission risks. The Science of the Total Environment, 751, 141750. https://doi.org/10.1016/j.scito tenv. 2020.141750

WHO (2020).WHO Director-General's opening remarks at the media briefing on COVID-19 - 11 March 2020.

WHO (2021). WHO announces simple, easy-to-say labels for SARSCoV-2 Variants of Interest and Concern.

Wilder, M. L., Middleton, F., Larsen, D. A., Du, Q., Fenty, A., Zeng, T., Insaf, T., Kilaru, P., Collins, M., Kmush, B., \& Green, H. C. (2021). Co-quantification of crAssphage increases confidence in wastewater-based epidemiology for SARS-CoV-2 in low prevalence areas. Water Research X, 11, 100100. https://doi.org/10. 1016/j.wroa.2021.100100

Wölfel, R., Corman, V. M., Guggemos, W., Seilmaier, M., Zange, S., Müller, M. A., Niemeyer, D., Jones, T. C., Vollmar, P., Rothe, C., Hoelscher, M., Bleicker, T., Brünink, S., Schneider, J., Ehmann, R., Zwirglmaier, K., Drosten, C., \& Wendtner, C. (2020). Virological assessment of hospitalized patients with COVID-2019. Nature, 581(7809), 465-469. https://doi.org/10. 1038/s41586-020-2196-x 
World Health. (2003). Guidelines for environmental surveillance of poliovirus circulation. World Health Organization.

Wu, F., Zhang, J., Xiao, A., Gu, X., Lee, W. L., Armas, F., Kauffman, K., Hanage, W., Matus, M., Ghaeli, N., Endo, N., Duvallet, C., Poyet, M., Moniz, K., Washburne, A. D., Erickson, T. B., Chai, P. R., Thompson, J., \& Alm, E. J. (2020). SARS-CoV-2 Titers in Wastewater Are Higher than Expected from Clinically Confirmed Cases. mSystems, 5(4), 00614. https://doi.org/10.1128/ mSystems.00614-20

Wu, Z., \& McGoogan, J. M. (2020). Characteristics of and Important Lessons From the Coronavirus Disease 2019 (COVID-19) Outbreak in China: Summary of a Report of 72314 Cases From the Chinese Center for Disease Control and Prevention. JAMA, 323(13), 1239-1242. https://doi.org/10.1001/jama.2020.2648

Wu, Y., Cheng, X., Jiang, G., Tang, H., Ming, S., Tang, L., Lu, J., Guo, C., Shan, H., \& Huang, X. (2021). Altered oral and gut microbiota and its association with SARS-CoV-2 viral load in COVID-19 patients during hospitalization. NPJ Biofilms Microbiomes., 7(1), 61. https://doi.org/10.1038/s41522-021-00232-5. PMID:34294722;PMCID:PMC8298611

Wurtz, N., Revol, O., Jardot, P., Giraud-Gatineau, A., Houhamdi, L., Soumagnac, C., Annessi, A., Lacoste, A., Colson, P., Aherfi, S., \& Scola, B. (2021). Monitoring the Circulation of SARSCoV-2 Variants by Genomic Analysis of Wastewater in Marseille, South-East France. Pathogens., 10(8), 1042. https://doi. org/10.3390/pathogens 10081042.PMID:34451505;PMCID: PMC8401729
Wurtzer, S., Marechal, V., Mouchel, J. M., Maday, Y., Teyssou, R., Richard, E., Almayrac, J. L., \& Moulin, L. (2020). Evaluation of lockdown effect on SARS-CoV-2 dynamics through viral genome quantification in waste water, Greater Paris, France, 5 March to 23. Euro Surveillance, 25(50), 2000776. https://doi.org/10.2807/ 1560-7917.ES.2020.25.50.2000776

Zhang, Y., Cen, M., Hu, M., Du, L., Hu, W., Kim, J. J., \& Dai, N. (2021). Prevalence and Persistent Shedding of Fecal SARS-CoV-2 RNA in Patients With COVID-19 Infection: A Systematic Review and Meta-analysis. Clinical and translational gastroenterology, 12(4): 00343. https://doi.org/10.14309/ctg.0000000000000343.

Yaniv, K., Ozer, E., Shagan, M., Lakkakula, S., Plotkin, N., Bhandarkar, N. S., \& Kushmaro, A. (2021). Direct RT-qPCR assay for SARSCoV-2 variants of concern (Alpha, B117 and Beta, B1351) detection and quantification in wastewater. Environmental. https://doi. org/10.1016/j.envres.2021.111653

Zhou, J. B., Kong, W. H., Wang, S., Long, Y. B., Dong, L. H., He, Z. Y., \& Liu, M. Q. (2021). Detection of SARS-CoV-2 RNA in Medical Wastewater in Wuhan During the COVID-19 Outbreak. Virologica Sinica. https://doi.org/10.1007/s12250-021-00373-Z

Publisher's Note Springer Nature remains neutral with regard to jurisdictional claims in published maps and institutional affiliations. 